\title{
The impacts of ICTs on tourism development: International evidence based on a panel quantile approach
}

\section{Chien-Chiang Lee ${ }^{1,2} \cdot$ Mei-Ping Chen ${ }^{3}(1) \cdot$ Wenmin $\mathrm{Wu}^{2} \cdot$ Wenwu Xing ${ }^{2}$}

Received: 3 September 2020 / Revised: 1 October 2021 / Accepted: 22 October 2021 /

Published online: 2 November 2021

(c) The Author(s), under exclusive licence to Springer-Verlag GmbH Germany, part of Springer Nature 2021

\begin{abstract}
Information and communication technologies (ICTs) have transformed the travel and leisure sector worldwide, yet until now there are no studies presenting international evidence of the different impacts of ICTs (i.e., Internet usage, secure Internet servers, mobile cellular subscriptions, high-technology export, communications as well as computer, and fixed broadband subscriptions) on tourism development (i.e., international traveler arrivals, increased international tourism receipts, and travel and leisure sector returns) by considering countries with different tourism development processes (e.g., high or low tourism development quantile). It is possible that ICTs have diverse or non-linear impacts on countries undergoing varying tourism development processes. Using international data based on a new panel quantile approach, this research thus aims to explore whether ICTs affect tourism development and looks into the possible asymmetric and non-linear relationships among the many variables. Results show that increasing mobile cellular subscriptions, secure Internet servers, and fixed broadband subscriptions have greater positive effects on traveler arrivals. ICTs also asymmetrically and non-linearly influence tourism across different quantiles. Non-global financial sub-periods and developing nations gain benefits from ICTs' establishment. Lastly, there are geographic differences in the ICTs-tourism nexus.
\end{abstract}

Keywords Tourism development - Information and communication technologies (ICTs) · Non-linear · Travel and leisure sector · Panel quantile regression

JEL Classification Z32 $\cdot \mathrm{C} 21 \cdot \mathrm{D} 83$

Mei-Ping Chen

meiping@ nutc.edu.tw

Extended author information available on the last page of the article 


\section{Introduction}

Information and communication technologies (ICTs) have transformed tourism worldwide and have provided a broad range of novel prospects for tourism growth (Aramendia-Muneta and Ollo-Lopez 2013). According to studies of the resourcebased view, technology resources are fundamental drivers to firms' performance (Ab Wahab et al. 2020), and a firm should consider its endowments to ensure that it always can competent with the best in whatever market it chooses to compete (Wernerfelt 1995). Currently, there is no research covering international empirical evidence of ICTs' impact on tourism activities by considering countries with different levels of tourism development. Therefore, this study expands into the global realm and uses a broader array of countries' data to explore the impacts of six kinds of ICTs on tourism development by examining different national tourism development levels in order to fill the gap in the literature and provide international evidence.

According to the World Travel and Tourism Council (WTTC 2019), one of the world's biggest economic sectors is travel and leisure, which in 2018 contributed US\$8.8 trillion to the worldwide economy, generated 319 million jobs (or $10 \%$ of total employment), and improved global GDP by $10.4 \%$. Travel and leisure, the second fastest developing sector in 2018 (only slightly behind manufacturing), has had a remarkable effect on the global economy. Additionally, it is now the most noteworthy service sector, becoming an agent of economic growth that has been broadly approved (Lee and Chang 2008; Lee et al. 2021; Wu et al. 2021; Wang and Lee 2022). Moreover, the elements swaying the flow of travelers around the world, such as nations' infrastructure, will remain and continue to affect tourists' behavior when choosing their vacation destinations. With approximately all nations seeking to attract global tourists, it is thus imperative to recognize the determining factors of this sector's receipts, tourists, and stock returns.

Travel and leisure form a highly information-intensive sector, and so its evolution is closely connected to the advance of new information technologies (Velázquez et al. 2015). Additionally, greater competition for international tourism has forced related organizations to adopt the latest ICTs in order to achieve a competitive edge as well as satisfactory growth (Abrhám and Wang 2017). This sector has broadly applied ICTs to cut costs, save on labor, increase operational efficiency, and most critically improve service quality and customer experience (Law et al. 2009). ICTs utilized for or through travel have become much faster, smaller, more intelligent, and more embedded in a user's situation. Moreover, the travel and leisure sector is characterized significantly by a long value chain affected by information. Hence, the creation, gathering, storage, retrieval, and transfer functions of ICTs remain as vital applications of all tourism companies (Januszewska et al. 2015). However, Brynjolfsson (1993) first proposes the notion of the "IT productivity paradox", noting that the benefits of spending by tourists are not present in output statistics.

Based on the resource-based view theory by Wernerfelt (1995), in order to achieve a certain competitive advantage a firm needs to consider its own 
endowment, its competitors, and its markets. We therefore empirically explore international evidence regarding whether ICTs help to positively attract international traveler arrivals (AR), increase international tourism receipts (RV), and improve travel and leisure sector returns (SR) under different tourism development levels of countries. Research confirms the strong non-linear correlations among ICTs, tourism, and macro-economic variables. For example, Adeola and Evans (2020) inspect the non-linear impacts of mobile phones and Internet in Africa and present a U-shape relation. Zaballos and López-Rivas (2012) reveal a non-linear relationship between fixed broadband subscriptions and economic conditions in Latin American and Caribbean countries. Likewise, Ketteni et al. (2007) present that a non-linear association exists between ICT capital and economic growth. Meo et al. (2018) show the asymmetric effects of economic factors on tourism demand. Most tourism relevant works utilizing the ordinary least squares (OLS) regression offer only an incomplete picture of a conditional distribution (Mosteller and Tukey 1977) and are unable to acquire the coefficients of the independent variables for the entire regression as a function of the change in tourism factors. Thus, this study uses the panel quantile regression (i.e., method of moment quantile regression, MMQR) approach proposed by Machado and Silva (2019) to explore the ICTs-tourism nexus in a cross-country framework.

Based on data availability, we use six mature ICTs (i.e., Internet usage, secure Internet servers, mobile cellular subscriptions, high-technology exports, communications as well as computer, and fixed broadband subscriptions) of 118 nations for the period 2006-2017. Our research investigates the following. (1) Whether ICTs have substantial impacts on international traveler arrivals. (2) Whether ICTs have substantial impacts on international tourism receipts. (3) Whether ICTs have substantial impacts on travel and leisure sector returns. (4) Does the association between ICTs and tourism development differ at diverse quantiles of the tourism distributions. Figure 4 depicts our conceptual framework and four hypotheses.

The contributions of this research to the existing literature of understanding the correlation between ICTs and tourism are articulated as follows. First, scant existing empirical studies explicitly highlight international evidence regarding the impacts of ICTs on tourism across different indicator (arrivals, receipts, and returns) quantiles. For example, Fernández et al. (2020), Kumar and Kumar (2020), Patwary et al. (2020), and Pierdicca et al. (2019) all use integrated data to explore the ICT-tourism nexus. Thus, our study is a forerunner to consider countries with specific levels of tourism development and provides international evidence in order to identify and formulate specific ICT-related policymaking of tourism destination nations.

Second, prior studies examining the effects of ICT on tourism development employ a limited number of different ICTs at one time for analysis, such as number of Internet users and mobile cellular subscriptions (Adeola and Evans 2020); websites, mobile apps, and touch screen (Pierdicca et al. 2019); mobile and broadband subscriptions (Kumar and Kumar 2020); international telecommunication services, news related transactions among non-residents and residents, computer data, and technical services (Shehzad et al. 2019); and mobile subscriptions (Kumar et al. 2019). Therefore, the existing literature does not specifically address the impacts of 
six different ICTs in a destination nation on tourism development (i.e., international traveler arrivals, tourism receipts, and sector returns).

Third, an ICT access and use has been recognized worldwide (Chinn and Fairlie 2007, 2010). However, there is still little international evidence from related literature. Many regional or country-specific related studies do exist-for example, Africa (Adeola and Evans 2020), U.S. (Akron et al. 2020), 28 countries (Choudhary et al. 2020), Latin American countries (Eugenio-Martin et al. 2004), Iran (Feshari 2017), and Israel (Kumar et al. 2019). Taking advantage of the large amount of worldwide data from World Development Indicators (WDI) issued by the World Bank database, our research employs cross-country data from 118 nations, provides global evidence, and generalizes the findings for wider global ICT applications in order to distinguish the differences in ICTs' impacts among countries with different tourism development levels.

Fourth and finally, Zaballos and López-Rivas (2012) pinpoint a non-linear association between fixed broadband subscriptions and economic condition. Ketteni et al. (2007) also reveal a non-linear association between ICT capital and economic development. Therefore, this study takes advantage of a new panel quantile regression (i.e., method of moment quantile regression, MMQR) approach proposed by Machado and Silva (2019) to specify how ICTs affect the entire conditional distribution of tourism development. MMQR offers a flexible tool to evaluate panel quantile regression, especially when the parameter estimations are hard or even impossible, thus producing reliable and robust results for policy formulations (Guo et al. 2020). This paper is a pioneering tourism study that applies MMQR to beneficially complement the present literature and has vital implications for countries across different tourism development levels.

Our findings show that secure Internet servers, mobile cellular subscriptions, and fixed-line broadband subscriptions have salient positive impacts on international traveler arrivals, while mobile cellular subscriptions and communication, computer notably and negatively affect tourism receipts for countries with the greatest tourism receipts. Mobile cellular subscriptions and high-technology exports (Internet usage, communication, computer, and fixed broadband subscriptions) negatively (positively) impact travel and leisure sector returns at different return quantiles. Thus, our findings support that ICTs in a destination nation determine traveler arrivals, tourism receipts, and sector returns. There is also salient evidence showing how ICTs asymmetrically and non-linearly influence tourism development across different quantiles. Further tests disclose that the relationships between ICTs and tourism development are robust after considering non-global financial sub-periods, endogeneity problems, and the countries' own economic development situations. European nations exhibit a different ICTs-tourism nexus. Interestingly, we find significantly positive impacts of the global financial crisis on sector returns at intermediate and higher return quantiles, suggesting that the travel and leisure sector can be a safehaven during the global financial crisis.

The rest of this study is organized as follows. Section 2 briefly reviews the literature and hypotheses. Section 3 illustrates the research methodology. Section 4 analyzes and discusses the empirical findings obtained. Section 5 concludes the research. 


\section{Literature review and hypotheses' development}

Regarding the resource-based view, Wernerfelt (1995) pinpoints that it is a truism that firms have different resource endowments and that it takes time and money to change these endowments. The same saying goes for many game-theoretic analyses (Rotemberg and Saloner 1994) that note how a firm employs its own resource endowments to achieve certain competitive goals. Wernerfelt (1995) argues that game-theoretic analyses are so general that they often depend neither on the identity of the firm nor its competitors, nor on that of its markets. In fact, firms almost always must do better or otherwise they will exit the market. Based on the viewpoint of Wernerfelt (1995) for considering the different endowments of countries, we expand to the country level, explore ICTs' impact on those countries with different levels of tourism development, and investigate their endowments, the whole markets, and their competitors in order to provide suggestions for economies undergoing different processes of tourism.

Zhago et al. (2019) note that with increasing technological advancement and its permeation into all aspects of human life, tourism sectors have applied a variety of technologies to facilitate travel activities that enhance travelers' destination experiences. Tcheng et al. (2007) disclose that the positive influences of ICT can be felt earlier, since ICT is similar to other utilities such as water, electricity, and transportation. As fixed investment has positive impacts on economic growth, investment in public infrastructure such as ICTs can enhance a country's overall development (Kpodar and Andrianaivo 2011). Waverman et al. (2005) also state that ICT investment is a form of cost savings, because communication utilities cut down transaction expenses. By decreasing the costs of retrieving information, ICT advances information flows, enables and improves price discovery, permits markets to function better, and helps regulate supply and demand (Kpodar and Andrianaivo 2011). The development of more sophisticated ICTs empowers both providers and destinations to increase efficiency and to implement a strategy in which re-engineered forms of communication dominate (Buhalis and Law 2008).

There are numerous studies probing the impacts of ICTs on tourism fields. For example, Mavri and Angelies (2009) use five European Union Mediterranean nations and find a salient positive relation between traveler arrivals and Internet usage. Ramos and Rodrigues (2013) use the number of Internet users in eighteen European nations, and show a positive association between number of online reservations and ICT. Kumar et al. (2019) note that mobile subscriptions can be utilized as a tool to enlarge tourism markets and visitor arrivals, mainly by keeping prospective tourism source markets informed. Adeola and Evans (2020) employ the number of Internet users and mobile cellular subscriptions to explore ICT's effect on tourism growth in African nations and present that ICT infrastructure has a positive and noteworthy influence on traveler arrivals. Kumar and Kumar (2020) indicate a unidirectional causality from mobile and fixed broadband subscriptions to both tourism demand and the destination nation's income.

The IT productivity paradox proposed by Brynjolffson (1993) conversely pinpoints the existence of negative impact of ICTs on productivity. The reason for the 
IT productivity paradox can be explained by the peer effect, time-lagging effect, and commoditization. Specifically, Gangopadhyay and Nilakantan (2021) explore the bank industry and address that although IT adoption can enhance firm productivity, resource use efficiency, and service quality through strengthening organizational capabilities, a proper assessment of costs and benefits of any type of new technology may be difficult for potential users, because IT has previously overlooked the influence of peer firms. Hwang et al. (2015) find that computers and Internet usage do not correlate to enhancing a firm's competitive advantage, since they are both now commoditized, such as IT being a form of infrastructural technology, like railroads and electricity (Carr 2003). Moreover, because it takes time for workforces to get adjusted to new ICTs, visitor arrivals only experience a positive impact in the long run, rather than in the short run (Kumar et al. 2019), implying the time-age effect of ICTs.

Aramendia-Muneta and Ollo-Lopez (2013) provide evidence that the usage of various ICTs has a slight influence on the level of competition as well as on greater productivity, while they have a positive influence on expanding the market share of companies. Although ICTs as a possible new competitive factor have been tested, Mihalič (2007) confirms a negative direct impact of ICT, proxied by Internet use, on the productivity of the travel sector and attribute the results to the ICT productivity paradox. Grace et al. (2003) denote that it may be challenging to form a causal connection between ICT and economic growth, because adverse influences might arise due to the opportunity costs of ICT investments and expenditures rather than in water, food, education, skills, etc. Safaeepour et al. (2015) analyze the influence of ICT on traveler arrivals and show that the effect of ICTs in tourism affairs is not noticeable. Sigala et al. (2004) demonstrate that productivity gains accrue not from investment per se, but from the entire utilization of ICT networking and informationalization abilities. Tsokota et al. (2017) indicate that simply having ICTs without any co-ordination, integration, and collaboration cannot attain sustainable development in the travel and leisure sector.

There is hence no consensus as to how ICTs impact tourism development. It is also doubtful that ICTs have any salient impact on AR. Thus, we form the following hypotheses to generalize the associations between ICT and AR internationally. Based on the literature mentioned above, we present the hypotheses as follows.

H1: ICTs have substantial impacts on international traveler arrivals.

Using the Granger causality test, Kumar and Kumar (2012) reveal a unidirectional causality going from capital stock to ICT and from ICT to tourism receipts. Using regression models, Al-Mulali et al. (2020) show that digital adoption has a positive impact on real tourism receipts for all their sub-sample groups (except highincome countries). Tsaurai and Chimbo (2019) find ICT has a positive influence on tourism receipts both in the long and short runs. Choudhary et al. (2020) confirm the importance of ICTs to an increase of tourism receipts. However, the correlation between tourism receipts and tourist arrivals is significant with 0.5 in coefficient's statistic regarding an unconditional correlation, and thus we realize that there exists differences between tourism receipts and traveler arrivals. Confronting the issue of the IT productivity paradox, it is doubtful that ICTs significantly impact RV via international evidence. Thus, we form the Hypothesis 2. 
H2: ICTs have substantial impacts on international tourism receipts.

Using regression analysis, Chen et al. (2005) indicate that among the macroeconomic variables, only money supply and the unemployment rate significantly explain the movement of hotel stock returns, while all non-macroeconomic factors selected (i.e., presidential elections, the 921 earthquake in Taiwan, the 2003 Iraqi war, the SARS outbreak in 2003, sports mega-events, the Asian financial crisis, and the 911 terrorist attacks) have significant influences on the hotel stock returns. Chen (2007) reveals that Chinese hotel stock returns are more sensitive to general macro-level variables. Non-macroeconomic events that could significantly impact Chinese hotel stock returns encompass financial crises, natural disasters, wars, terrorist attacks, political events, and sports mega-events. Chen et al. (2012) indicate that the discount rate, unemployment rate, and oil price could significantly affect Japanese hotel stock returns and serve as significant determinants of these returns. Demir et al. (2017) present that the consumer confidence index, exchange rate, and foreign tourist arrivals could Granger cause tourism stock returns. Until now, few studies have addressed ICTs' impacts on tourism stock returns. Built on the abovementioned literature, we hypothesize that ICTs influence travel and leisure sector returns and form the following hypothesis.

H3: ICTs have substantial impacts on travel and leisure sector returns.

Most tourism related works utilizing OLS offer only an incomplete picture of a conditional distribution (Mosteller and Tukey 1977) and are unable to acquire the coefficients of the independent variables for the entire regression as a function of the change in tourism factors. Additionally, Chiu and Yeh (2017) discover strong evidence of a non-linear relation between tourism development and economic growth, suggesting that it is not continuous and constant. Adeola and Evans (2020) find nonlinear impacts of mobile phones and Internet usage in Africa's tourism sector that present a U-shape relation. Zaballos and López-Rivas (2012) reveal a non-linear relationship between fixed broadband subscriptions and the economic conditions in Latin American and Caribbean countries. Ketteni et al. (2007) present a non-linear association between ICT capital and economic growth. Meo et al. (2018) find asymmetric effects of economic factors on tourism demand. Thus, this study uses MMQR to probe the ICTs-tourism nexus under different tourism development quantiles and forms the next hypothesis.

H4: The association between ICTs and tourism development differs at diverse quantiles of the tourism distribution.

Compared to foreign traveler arrivals, Chen (2007) reveals that general macrolevel elements are more sensitive to hotel stock returns. Tourism is also regarded as a vital means at overwhelming the macroeconomic problems via improving the balance of payments and generating income, taxes, hard currency, and jobs (Lee and Brahmasrene 2013). Tourism relates closely to economic development and socioeconomic growth, not only for numerous developing nations, but also for some developed nations (Shahzad et al. 2017). Demir et al. (2017) present that growths in exchange rate and foreign traveler arrivals have a close correlation. Thus, we comprise GPD per capita growth rate (GDP), real exchange rate (EXG), inflation (INF), and unemployment (UMP) as control variables. 


\section{Methodology}

\subsection{Data}

\subsubsection{Independent variables}

Figure 4 depicts our research framework. This study examines international evidence of the different impacts of ICTs (i.e., Internet usage, secure Internet servers, mobile cellular subscriptions, high-technology exports, communications as well as computer, and fixed broadband subscriptions) on tourism development (i.e., international traveler arrivals, increased international tourism receipts, and improved travel and leisure sector returns) by considering countries with different tourism development processes (e.g., high or low tourism development quantile). Compared to the large majority of related quantitative studies (e.g., Bethapudi 2013; Bizirgianni and Dionysopoulou 2013) using questionnaires that suffer the shortcomings of particular populations, self-selection bias, and collected samples from limited sets (Wright 2005), our analysis covers data on ICTs from the WDI issued by the World Bank Database. ${ }^{1}$

Andrianaivo and Kpodar (2011) use growth in personal computer users and Internet users to probe the influence of ICT on economic growth in African countries. Adeola and Evans (2020) use the number of Internet users (\% of population) and mobile cellular subscriptions (\% of population) to explore the association between ICTs and African tourism development. Kumar and Kumar (2020) indicate a unidirectional causality from mobile and fixed broadband subscriptions to both tourism demand and the destination nation's income. Choudhary et al. (2020) employ computer, communication, and other services, Internet users, secure Internet servers, and mobile cellular subscriptions to explore the relationship between ICTs and tourism in 28 countries. Gooroochurn and Sugiyarto (2005) discuss an innovative approach for measuring tourism competitiveness using high-technology exports for over 200 countries and find that the factor of hightechnology exports has an important influence.

Following these studies, our ICT indices are proxied by six variables: (1) Individuals using the Internet, \% of population (INT); (2) Secure Internet servers, per 1 million people (SEC); (3) Mobile cellular subscriptions, per 100 people (MOB); (4) High-technology exports, \% of manufactured exports (TEX); (5) Communications, computer, etc., \% of service exports (CCE); and (6) Fixed broadband subscriptions, per 100 people (FBS). Table 10 main variable list in Appendix identifies all variables employed by our study.

\subsubsection{Dependent variables}

Utilizing the ratio of international tourism receipts to total exports, Sreekumar and Parayil (2002) investigate tourism as a growth choice. Gokovali (2010) also employs

\footnotetext{
${ }^{1}$ World Development Indicators (WDI) is the primary World Bank collection of development indicators, compiled from officially recognized international sources. It presents the most current and accurate global development data available and includes national, regional, and global estimates. The ICTs and tourism related literature use WDI data, such as Kumar and Kumar (2012), Kumar and Kumar (2020), Al-Mulali et al. (2020), and Choudhary et al. (2020).
} 
the ratio of international tourism receipts to total exports so as to explore the contribution of tourism to economic growth. Eugenio-Martin et al. (2004) use the number of traveler arrivals to study the association between that datapoint and economic growth. Chen (2011) takes tourism sector stock returns to assess the performance of supply-side investments in the tourism sector.

Following the abovementioned literature, the three dependent variables of tourism development used herein are log difference of international traveler arrivals (AR), log difference of international tourism receipts (percentage of total exports) (RV) from the World Bank database, and travel and leisure sector yearly price index from the DataStream database. Sector returns $(\mathrm{SR})$ are estimated by $\left(P_{t}-P_{t-1}\right) /$ $P_{t-1}$, where $P_{t}$ is the adjusted closing price index at time $t$ in US dollars. Because the latest data of AR and RV are for the year 2017, our empirical study uses 118 nations that possess AR and RV data, and our study period is 2006-2017. Table 11 Sample nation list provides the sample nations.

\subsubsection{Control variables}

Chiu and Yeh (2017) denote that tourism development has a salient relation with inflation and exchange rate changes. Chen (2007) gauges the relationships between macro-level explanatory factors and Chinese hotel stock returns by employing the consumer price index and total foreign traveler arrivals. Castro-Nuño et al. (2013) show a positive association exists between GDP and tourism. Perles-Ribes et al. (2016) note the unemployment influence of economic crises on hotel and residential tourism destinations. We thus account for the impact of economic elements by comprising EXG (log of real exchange rate, real exchange rate estimates by the destination country's official exchange rate*US CPI/destination country's CPI), GDP (GDP per capita growth, annual \%), INF (inflation, consumer prices, annual \%), and UMP (log difference of unemployment, total $\%$ of total labor force). All data are collected in US dollars. Four control factors are from the World Bank database.

Following Divino and McAleer (2010) in which the log difference has sensible interpretations, we use the log difference forms of all variables, except for SR, which has negative values and GDP, INF, and EXG. EXG is in log form. As tourism involves discretionary income, it is anticipated during a tough economy that people may choose to save their cash for the necessities of life such as food, shelter, and family supplies (Papatheodorou et al. 2010). Therefore, according to Ntim et al. (2013), we identify the global financial crisis period as 2008-2009. ${ }^{2}$ Balli et al. (2019) estimate traveler arrivals by controlling regional structural changes. EugenioMartín et al. (2004) discover that the nexus between the number of traveler arrivals and economic development does exist in developing nations, but not in developed nations. Therefore, to conduct an inclusive investigation we split the sample data

\footnotetext{
${ }^{2}$ Regarding the defined period of the global financial crisis, we use information on system banking crises to establish the crisis year (Allen et al., 2012; Bretschger et al., 2012; Laeven and Valencia, 2012; Chen et al., 2019), and the starting years for the banking crises are as follows: the crisis in the U.S. and U.K. commenced in 2007, started in 2008 for all other countries, and followed through in 2009. The crisis data are given by a simple binary variable that equals one if country $i$ had the crisis start in years 2008 and 2009 and zero otherwise.
} 
Table 1 Descriptive statistics

\begin{tabular}{lrrrllllll}
\hline & \multicolumn{1}{l}{ Mean } & Median & \multicolumn{1}{l}{ Max } & Min & STD & Skew & Kurtosis & Jarque-Bera & Obs \\
\hline AR & 2.454 & 2.248 & 27.440 & -24.008 & 4.988 & -0.465 & 11.014 & 585.860 & 1335 \\
RV & 1.109 & 1.123 & 43.753 & -27.118 & 6.589 & 1.155 & 14.658 & 1271.170 & 1317 \\
SR & 0.067 & 0.000 & 5.267 & -0.808 & 0.532 & 5.090 & 45.939 & $17,526.860$ & 595 \\
INT & 2.469 & 1.561 & 31.808 & -32.883 & 4.776 & -0.028 & 23.715 & 3862.171 & 1322 \\
SEC & 22.606 & 15.099 & 92.791 & -0.093 & 18.224 & 1.549 & 4.975 & 121.514 & 936 \\
MOB & 0.675 & 0.656 & 7.818 & -16.105 & 2.613 & -1.273 & 11.350 & 685.887 & 1403 \\
TEX & -0.234 & 0.325 & 133.717 & -109.333 & 14.898 & 1.512 & 47.189 & $17,656.260$ & 1045 \\
CCE & 0.031 & 0.402 & 28.331 & -22.314 & 4.606 & 0.414 & 13.238 & 949.590 & 1322 \\
FBS & 2.644 & 1.843 & 25.211 & -7.177 & 3.665 & 2.466 & 13.387 & 1189.875 & 1349 \\
GDP & 1.931 & 1.723 & 9.424 & -5.843 & 2.428 & 0.166 & 4.040 & 10.733 & 1387 \\
INF & 3.078 & 2.345 & 29.502 & -1.418 & 3.576 & 2.735 & 17.003 & 2033.859 & 1352 \\
EXG & 1.130 & 0.833 & 3.865 & -0.224 & 1.017 & 0.716 & 2.609 & 19.838 & 1380 \\
UMP & -1.062 & -0.824 & 13.861 & -12.449 & 3.914 & 0.103 & 4.659 & 25.143 & 1404 \\
\hline
\end{tabular}

Notes: The yearly data in this study span from 2006/01/01 to 2017/12/31. 'Min', 'Max', and 'STD' are respectively the minimum, maximum, and standard deviation. AR (number of international inbound travelers), RV (international tourism receipts, \% of total exports), SR (country travel and leisure sector returns), INT (individuals using the Internet, \% of population), SEC (secure Internet servers, per 1 million people), MOB (mobile cellular subscriptions, per 100 people), TEX (high-technology exports, \% of manufactured exports), CCE (communications, computer, etc., $\%$ of service exports), FBS (fixed broadband subscriptions, per 100 people), GDP (GDP per capita growth, annual \%), INF (inflation, consumer prices in annual \%), EXG (real currency exchange rate per US\$), and UMP (unemployment, total \% of total labor force). All the variables are in log difference form, except for SR, which has negative values and GDP, INF, and EXG. EXG is in log form. The six ICT factors are INT, SEC, MOB, TEX, CCE, and FBS. The Jarque-Bera (JB) statistics of all variables indicate departures from normality and present the existence of non-linear components in the data-generating process

into three subgroups: developing nation, non-global financial crisis, and European nations. Most of our sample nations (33) are in Europe.

\subsubsection{Descriptive statistics of variables}

Table 1 provides summary statistics of our main variables. Results from Table 1 show that SR varies between $-0.808 \%$ and $5.267 \%$ during the sample period, with the median being $0.00 \%$ and the average being $0.067 \%$. The travel and leisure sector returns are positively skewed, suggesting that the tail on the right side of the possibility density function is fatter than that on the left side. The kurtosis coefficients are greater than 45.939 for SR, indicating that the series have fatter tails than other dependent variables. Additionally, the distributions are asymmetric. The average RV is 1.109 , and the range fluctuates between -27.118 and 43.753 with a 6.589 standard deviation during the sample period, suggesting large dissimilarities among nations' tourism receipts. The mean AR is 2.454 , and the range fluctuates between -24.008 and 27.44 with a 4.988 standard deviation. 
Table 2 displays the unconditional correlation between variables. The correlation between AR and RV is significantly positive. Among the six ICT variables, SR saliently and negatively relates to SEC. RV notably and negatively relates to CCE, whereas it notably and positively relates to TEX. Nevertheless, AR notably and negatively correlates to CCE. GDP is saliently positive with AR, which is consistent with Saha and Yap (2014), suggesting that governments in high-income countries can afford to invest funds toward building up and maintaining infrastructures for the tourism industry, which in turn attract more tourists with an expectation that high income increases demand for tourism. Castro-Nuño et al. (2013) also show a positive relationship between GDP and tourism. We find a negative impact of UMP and AR, which is in line with Inchausti-Sintes (2015) in that tourism promotes economic growth and reduces unemployment. The positive relation of the real exchange rate with AR and RV is similar to Ghartey (2013), whereby in the long run, tourism growth causes currency depreciation (an increase in the real exchange rate), suggesting that the depreciation increases traveler arrivals and real expenditures. The negative relation between inflation and SR is in line with Fama (1981), who says that common stock returns and inflation are negatively related. The positive relation between inflation and RV is inconsistent with Meo et al. (2018). It is expected that tourism demand responds asymmetrically to inflation, because a rise in inflation increases the travel and living costs of tourists and reduces their purchasing power. On the other hand, a decline in inflation increases purchasing power, and more tourists can visit the host country (Meo et al. 2018).

The panel unit-root test results show a uniform conclusion that the variables are stationary in level form. The probabilities for the Levin, Lin, and Chu tests are computed using an asymptotic Chi-square distribution. All other tests assume asymptotic normality. The maximum lag lengths are automatic selection, and Schwarz Bayesian Criterion is used to determine the optimal lag length. Due to space limitation, results of panel unit-root tests are not shown, but are available from the authors upon request.

\subsection{Models}

Conventional OLS provides summary point estimations for the average results of the explanatory variables (Binder and Coad 2011). Focusing on the average impacts may under- or over-estimate the relevant coefficient estimates or may even fail to recognize vital associations (Binder and Coad 2011). Taking the unobserved individual heterogeneity and distributional heterogeneity into account, Lv and $\mathrm{Xu}$ (2017) examine the impact of corruption on tourism demand by using the panel quantile regression approach. Menegaki et al. (2020) explore aggregate tourist demand in Europe with a panel quantile regression approach. Hence, OLS, which can depict the association at the average level, might lead to misspecification, and information around the tails of a distribution will be overlooked.

Meo et al. (2018) find a long-run asymmetric relationship between inflation and tourism demand and apply a linear symmetric model for tourism demand, 


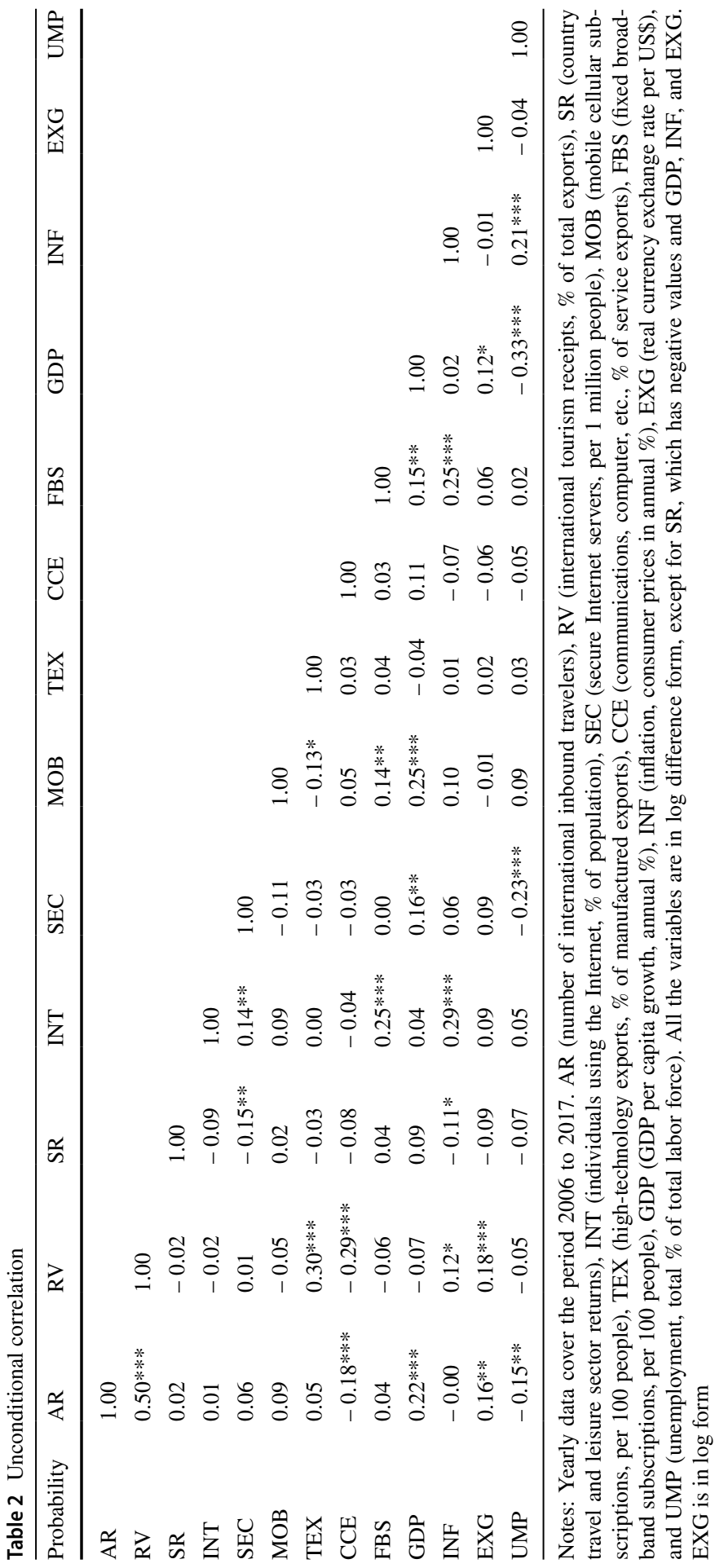


which could be misleading. Chiu and Yeh (2017) pinpoint that if one ignores the probability that the tourism-economic development nexus could be non-linear, then the findings of a linear model often cause bias due to using a false assessment method (Lee et al. 2020). Zaballos and López-Rivas (2012) present a nonlinear connection between fixed broadband subscriptions and economic conditions. Ketteni et al. (2007) also reveal a non-linear association between ICT capital and economic growth.

MMQR offers a flexible tool to evaluate panel quantile regression, especially when the parameter estimations are hard or even impossible to calculate, thus producing reliable and robust results for policy formulations (Guo et al. 2020). Using MMQR proposed by Machado and Silva (2019) to control for distributional heterogeneity, Lee and Chen (2020) explore the effects of country risks on tourism development. Applying MMQR, Guo et al. (2020) analyze the impacts of influential factors on $\mathrm{CO}_{2}$ emissions at various quantiles and control for diverse econometric challenges such as endogeneity and heterogeneity. Elheddad et al. (2020) employ MMQR to estimate models with fixed effects and models with endogenous explanatory variables.

The MMQR approach is thus applied to appraise whether ICT variables influence AR, RV, and SR by intensifying the descriptive statistics in Table 1 and testing Eqs. (1), (2), and (3) by utilizing AR, RV, and SR as dependent variables, respectively.

$$
\begin{aligned}
& \mathrm{AR}_{\mathrm{it}}=\alpha_{0}+\alpha_{1} \mathrm{ICT}_{\mathrm{i}, \mathrm{t}}+\alpha_{2} \mathrm{CV}_{\mathrm{i}, \mathrm{t}}+\varepsilon_{\mathrm{it}} \\
& \mathrm{RV}_{\mathrm{it}}=\alpha_{0}+\alpha_{1} \mathrm{ICT}_{\mathrm{i}, \mathrm{t}}+\alpha_{2} \mathrm{CV}_{\mathrm{it}}+\varepsilon_{\mathrm{it}} \\
& \mathrm{SR}_{\mathrm{it}}=\alpha_{0}+\alpha_{1} \mathrm{ICT}_{\mathrm{i}, \mathrm{t}}+\alpha_{2} \mathrm{CV}_{\mathrm{i}, \mathrm{t}}+\varepsilon_{\mathrm{it}}
\end{aligned}
$$

Here, tourism development's $\mathrm{AR}_{\mathrm{it}}, \mathrm{RV}_{\mathrm{it}}$, and $\mathrm{SR}_{\mathrm{it}}$ represent nation $i$ 's international traveler arrivals, tourism receipts, and travel and leisure sector returns in time $t . \mathrm{ICT}_{\mathrm{it}}$ denotes the six ICT proxies: INT (individuals using the Internet, $\%$ of population), SEC (secure Internet servers, per 1 million people), MOB (mobile cellular subscriptions, per 100 people), TEX (high-technology exports, \% of manufactured exports), CCE (communications, computer, etc., \% of service exports), and FBS (fixed broadband subscriptions, per 100 people). CV is the four macroeconomic control variables and three dummy variables (i.e., economic development state, European country, and global crisis period) that might sway AR, RV, and SR: GDP (GDP per capita growth, annual \%), INF (inflation, consumer prices in annual \%), EXG (real exchange rate), and UMP (unemployment, total $\%$ of total labor force). All the variables are in log difference form, except for dummy variables, SR (which has negative values), GDP, INF, and EXG. EXG is in $\log$ form.

We estimate Eqs. (1), (2), and (3) by the MMQR models to explore H1-H4. Equations (1)-(3) can answer the question of "whether ICT symmetrically affects tourism development (i.e., H1-H3)". However, it does not solve the problem of whether 
"ICT affects tourism development differently for countries with different levels of tourism development (H4)". From the viewpoint of policy-making, it is more interesting to understand what happens in extreme cases. To answer these questions, quantile regression can be very useful. It is an extensive form based on the traditional regression and offers a complete picture of a conditional distribution. For our study, this method helps obtain the entire influences of ICTs across the full distribution of tourism development. Furthermore, this model is robust to outliers, heteroskedasticity, and skewness (Koenker and Hallock 2001).

We write the model as follows:

$$
M_{y_{t}}\left(\partial \mid x_{t}\right)=\alpha_{\partial}+x_{t}^{T} \beta_{\partial},
$$

where $0<\partial<1, M_{y t}\left(\partial \mid x_{t}\right)$ denotes the $\partial$ th conditional quantile of $y_{t}, x_{t}$ denotes all the determinants, and $\beta_{\partial}$ and $\alpha_{\partial}$ are the estimated parameters and unobserved effects at the $\partial$ th quantile. It is obvious that the above equation does not account for unobserved individual heterogeneity. ${ }^{3}$ Thus, Eq. (4) is improved as the following a panel quantile regression form:

$$
M_{y_{i t}}\left(\partial \mid \alpha_{i}, x_{i t}\right)=x_{i t}^{\prime} \beta_{\partial}+\alpha_{i} .
$$

Machado and Silva (2019) suggest a new panel quantile regression model via moments. The approach of Machado and Silva (2019) has a unique advantage in the non-linear model and makes the calculation simpler, particularly when several endogenous variables exist. Following Machado and Silva (2019), we form the following equation:

$$
y_{i t=} \alpha_{i}+x_{i t}^{\prime} \beta+\varnothing\left(\omega_{i}+N_{i t}^{\prime} \tau\right) H_{i t},
$$

where $N_{i t}$ is known differentiable (with probability) transformations of $x_{i t}, \varnothing($.$) is a$ known $\ell^{2}$ function such that $\mathrm{P}\left(\varnothing\left(\omega_{i}+N_{i t}^{\prime} \tau\right)\right)=1$, and $H_{i t}$ is an unobserved random variable. Specifically, $H_{i t} \perp x_{i t}, \mathrm{E}(H)=0$, and $\mathrm{E}(|H|)=1$. From Eq. (6), we obtain:

$$
M_{y_{i t}}\left(\partial \mid x_{i t}\right)=\alpha_{i}+x_{i t}^{\prime} \beta+\varnothing\left(\omega_{i}+N_{i t}^{\prime} \tau\right) m(\partial),
$$

where $m(\partial)=F_{H}^{-1}(\partial)$, and hence $\mathrm{P}(\mathrm{H}<\mathrm{m}(\partial))=\partial$. When $\varnothing($.$) is the identity func-$ tion and $\mathrm{N}_{i t}=x_{i t}$, Eq. (7) can be simplified to:

$$
M_{y_{i t}}\left(\partial \mid x_{i t}\right)=\left(\alpha_{i}+\omega_{i} m(\partial)\right)+x_{i t}^{\prime} \beta+x_{i t}^{\prime} \tau m(\partial),
$$

where $\alpha_{i}(\partial)=\alpha_{i}+\omega_{i} m(\partial)$ represents the $\partial$ th quantile fixed effect for country $i$. Unlike the usual quantile fixed effect, this differs from the location shift-that is, this approach allows the time-invariant individual characteristic to distinctly affect

\footnotetext{
${ }^{3}$ Compared to time series data, the advantages of panel data include an increased amount of observations and corresponding variations and a reduction of noise caused by individual time series regression (Westerlund et al., 2015).
} 
the conditional distribution of $y_{i t}$ across countries. The marginal effect of variable $x_{i t, k}$ on the $\partial$ th quantile of $y_{i t}$ is $\beta_{k}+m(\partial) \times \rho \varnothing\left(\omega_{i}+N_{i t}^{\prime} \tau\right) / \rho x_{i t, k}$.

\section{Results}

\subsection{Influences of ICTs on international traveler arrivals (H1)}

We report the results from quantile analysis in Eq. (1) in Table 3 in terms of estimates of the MMQR-based international traveler arrival models. Regarding panel quantile regression estimates with $95 \%$ confidence intervals for the impacts of the independent variables on international traveler arrivals, Fig. 1 provides summary charts for the MMQR results. We estimate the quantiles, from the lower one $(q=0.1)$ to the higher one $(q=0.9)$, all of which divide AR. The non-linear effects of ICT are explored by considering different AR distributions. Figure 1 shows the marginal effect of the six ICT variables for all quantiles within the $(0,1)$ range of AR. Figure 1 offers the non-linear findings that ICT asymmetrically affects AR at lower and upper quantiles.

We draw some interesting findings about ICTs' non-linear effects on AR. First, the effects of FBS are constantly positively significant at all quantiles, and the coefficients of two extreme quantiles are larger than those coefficients of the others, indicating that increasing FBS leads to higher AR for all AR quantiles. Our findings expand the results of Thompson and Garbacz (2011) in that low-income nations derive considerably benefit from mobile broadband services. Second, INT, TEX, and CCE show no salient impacts on AR. Third, MOB and SEC are considerably positively associated to $\mathrm{AR}$ at several quantiles, implying that increasing $\mathrm{MOB}$ and SEC non-linearly leads to higher AR at lower to higher quantiles. The MOB finding is consistent with Choudhary et al. (2020), whereby mobile cellular subscriptions have a positive effect on tourism development. Rajan et al. (2016) states that an increase in the number of secure Internet servers results in a rise by the number of tourism arrivals. Because of the inconsistent impacts of SEC and MOB, we conclude that the non-linear, positive, and significant effects of MOB and SEC influence AR trends. Taking ICTs into account helps tourism participants to realize the ICT determinants of AR. Thus, our results support Hypothesis H1 in that ICTs have positive and significant effects on international traveler arrivals. Likewise, Adeola and Evans (2020) find when ICT and infrastructure increase in African nations that the level of traveler arrivals also increases.

Regarding control variables, GDP positively influences AR. Similarly, Saha and Yap (2014) note that governments in high-income countries can afford to invest funds toward building up and maintaining infrastructures for the tourism industry, which in turn attract more tourists, expecting that high income increases demand for tourism. Castro-Nuño et al. (2013) also display a positive association between GDP and tourism. INF shows asymmetric correlations with AR; i.e., a negative (positive) relation at lower (higher) quantiles, which is consistent with the finding of Meo et al. (2018) who present a long-term asymmetric association between inflation and 


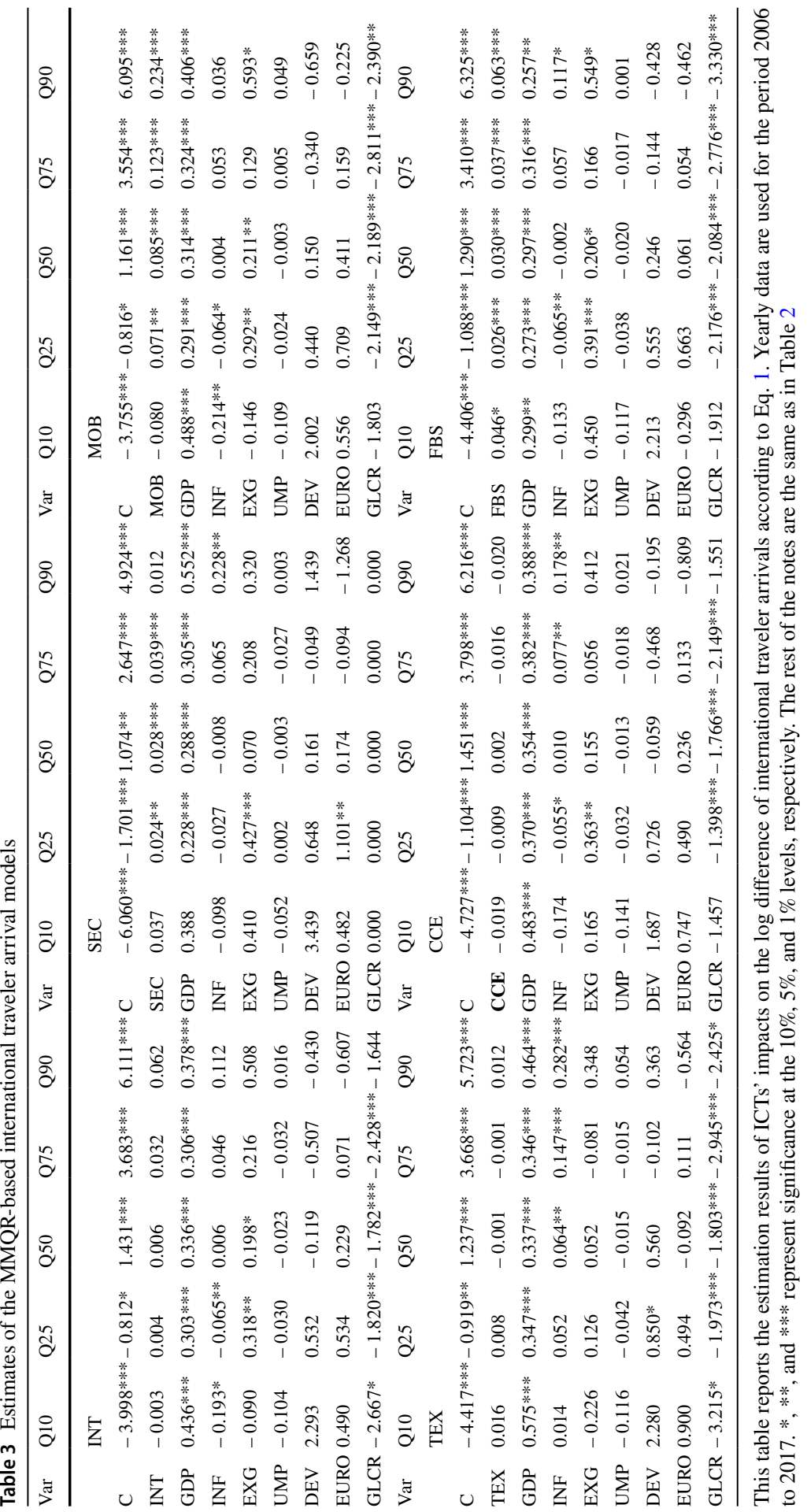



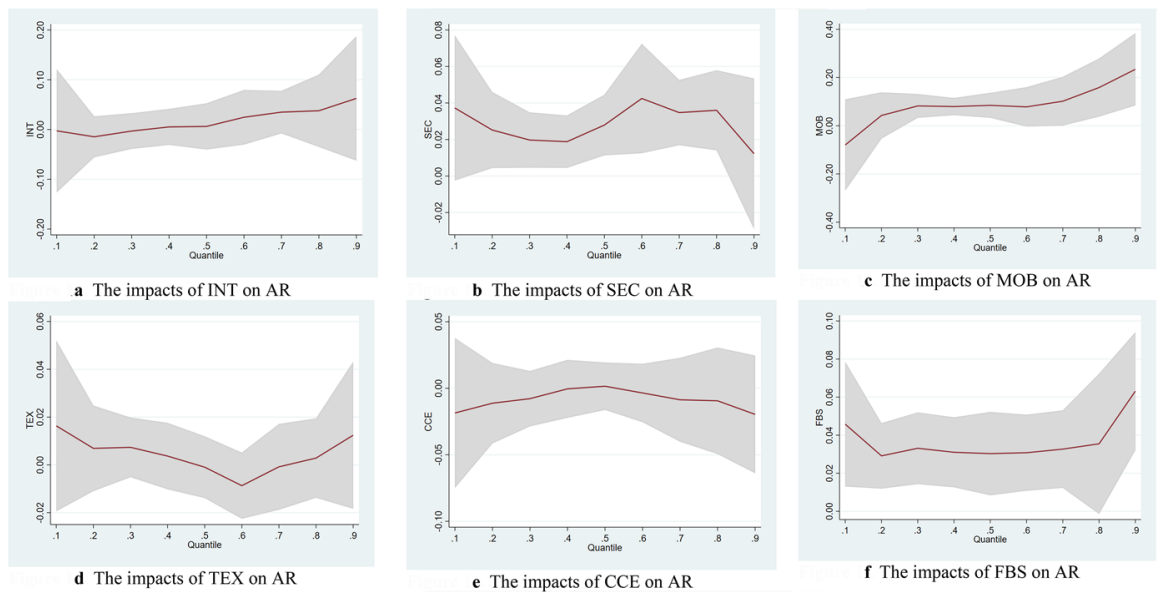

Fig. 1 Panel quantile regression estimates with $95 \%$ confidence intervals for the impacts of the independent variables on international traveler arrivals. The shaded area shows the quantile regression estimates for the quantiles ranging from 0.1 to 0.9 , a solid line is the estimates, and the grey area depicts lower and upper bounds of the $95 \%$ confidence intervals for the quantile regression estimates

tourism demand. UMP shows no salient link with AR. EXG is positively linked with AR and is consistent with Ghartey (2013) who note in the long run that tourism growth causes currency depreciation (an increase in the real exchange rate), suggesting that depreciation increases traveler arrivals and real expenditures. Developed countries and European countries show salient positive impacts on AR quantiles, whereas GLCR shows generally salient negative impacts on AR quantiles. Thus, AR is sensitive to macroeconomic variables.

\subsection{Influences of ICTs on international tourism receipts (H2)}

Table 4 displays quantile assessments from Eq. (2). Figure 2 presents MMQR parameter estimates along with the $95 \%$ confidence intervals (solid lines) for the predictive power of ICT variables' influence on RV. Figure 2 displays that the estimated 95\% confidence intervals for the impacts of MOB, TEX, and FBS on international tourism receipts are smaller, signifying that these variables can work as determinants in identifying RV. For the ICT variables in Table 4 regarding the estimates of the MMQR-based international tourism receipt models, MOB remarkably and negatively affects RV at the 25th-50th quantiles, and CCE consistently, notably, and negatively impacts RV for the entire quantiles. This implies that MOB and CCE establishment costs might lead tourism receipts to decrease. Thus, we should explore further as to whether these negative MOB and CCE impacts are consistent with the IT productivity paradox of Brynjolfsson (1993) in which the benefits of spending do not show up in statistics. TEX and FBS have a positive noteworthy effect at the 90th quantile, meaning that the highest RV nations could increase TEX and FBS to improve RV. Thus, our results partially support Hypothesis H2 that CCE, TEX, and 


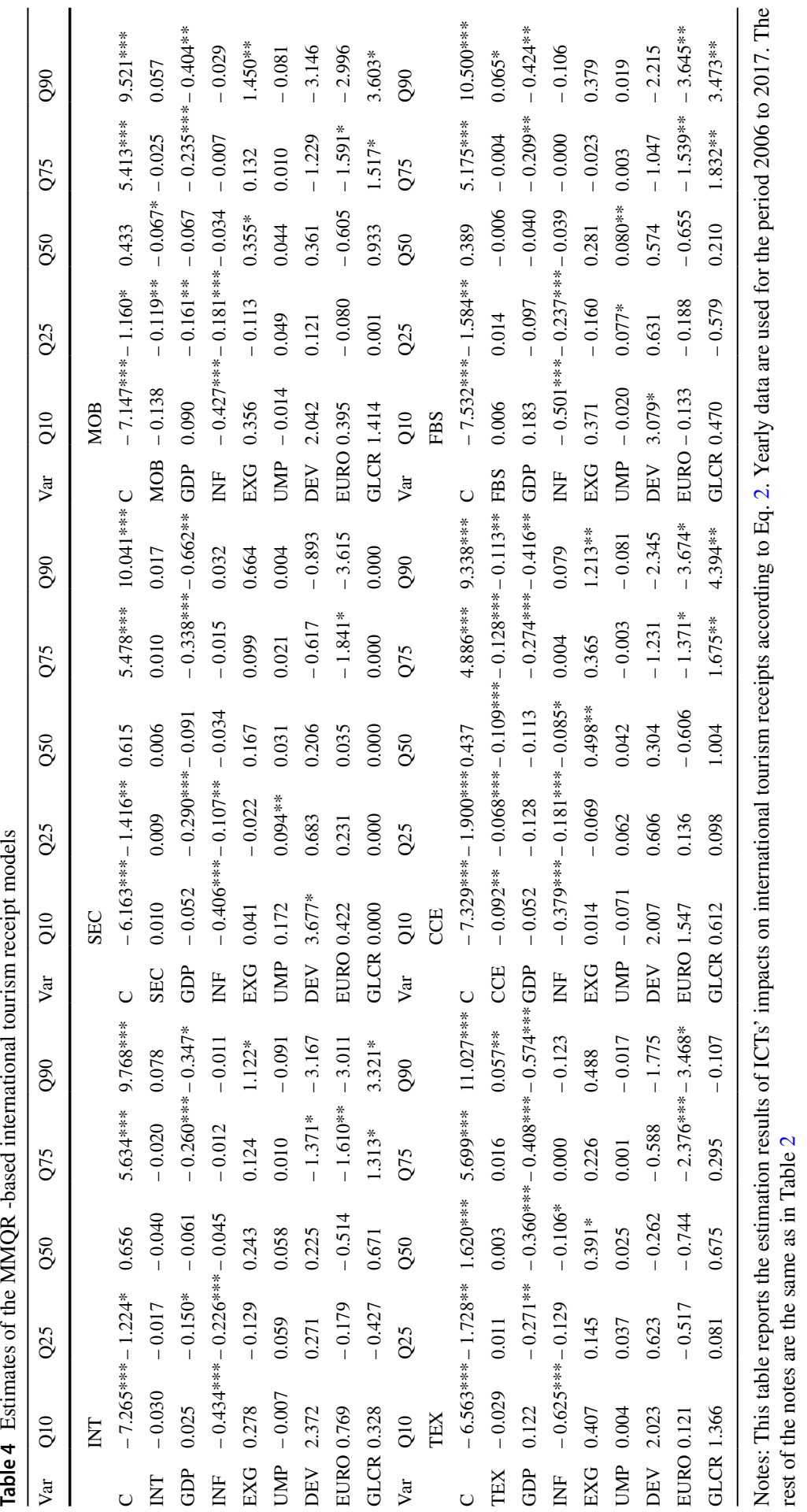



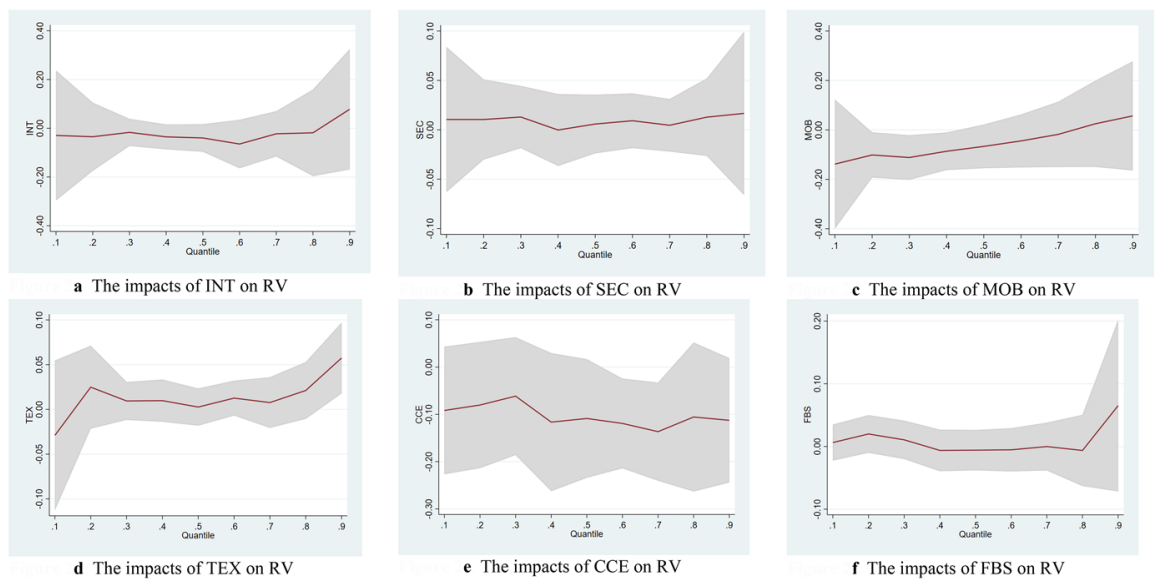

Fig. 2 Panel quantile regression estimates with 95\% confidence intervals for the impacts of the independent variables on international tourism receipts. The same as in Fig. 1

FBS have noteworthy impacts on international tourism receipts. To sum up, we find that CCE negatively affects all RV quantiles.

We next present that the influences of MOB, TEX, and FBS on RV are non-linear across the quantiles. Comparing the influences of ICT variables in Tables 3 and 4, the ICT indices display more noticeable positive effects on AR than on RV. The probable reasons for the significance of ICTs on AR than on RV are followings: First, AR can be more directly and immediately used to estimate tourism development. RV is largely influenced by several macroeconomic factors, such as exchange rate, inflation, oil prices etc. However, for ICTs' impacts on RV, one needs time to convert ICT capitals into revenues. Second, as mentioned above, the IT productivity paradox whether and how IT investment leads to higher market value and/or performance remains in question. Brynjolfsson (1993) suggests IT usage should consider the time lag effect, which refers to after IT investment it may take some time to create profits.

Regarding the control variables, GDP and INF display negative influences on $\mathrm{RV}$ at some of the quantiles, denoting that lower GDP and an INF economy might inspire greater RV. UMP has positive impacts at some quantiles, which implies that higher UMP can cut costs in the travel and leisure sector, leading to a higher RV. EXG is positively linked with AR, which is consistent with the finding of Table 3 that currency depreciation (an increase in the real exchange rate) increases traveler arrivals and real expenditures. Developed countries show a mixed impact on RV quantiles, while European countries show salient negative impacts on RV quantiles. Interestingly, GLCR show saliently positive impacts on RV at higher quantiles, implying that higher RV countries gain tourism receipts especially during the global financial crisis. Thus, RV is sensitive to the control variables. 


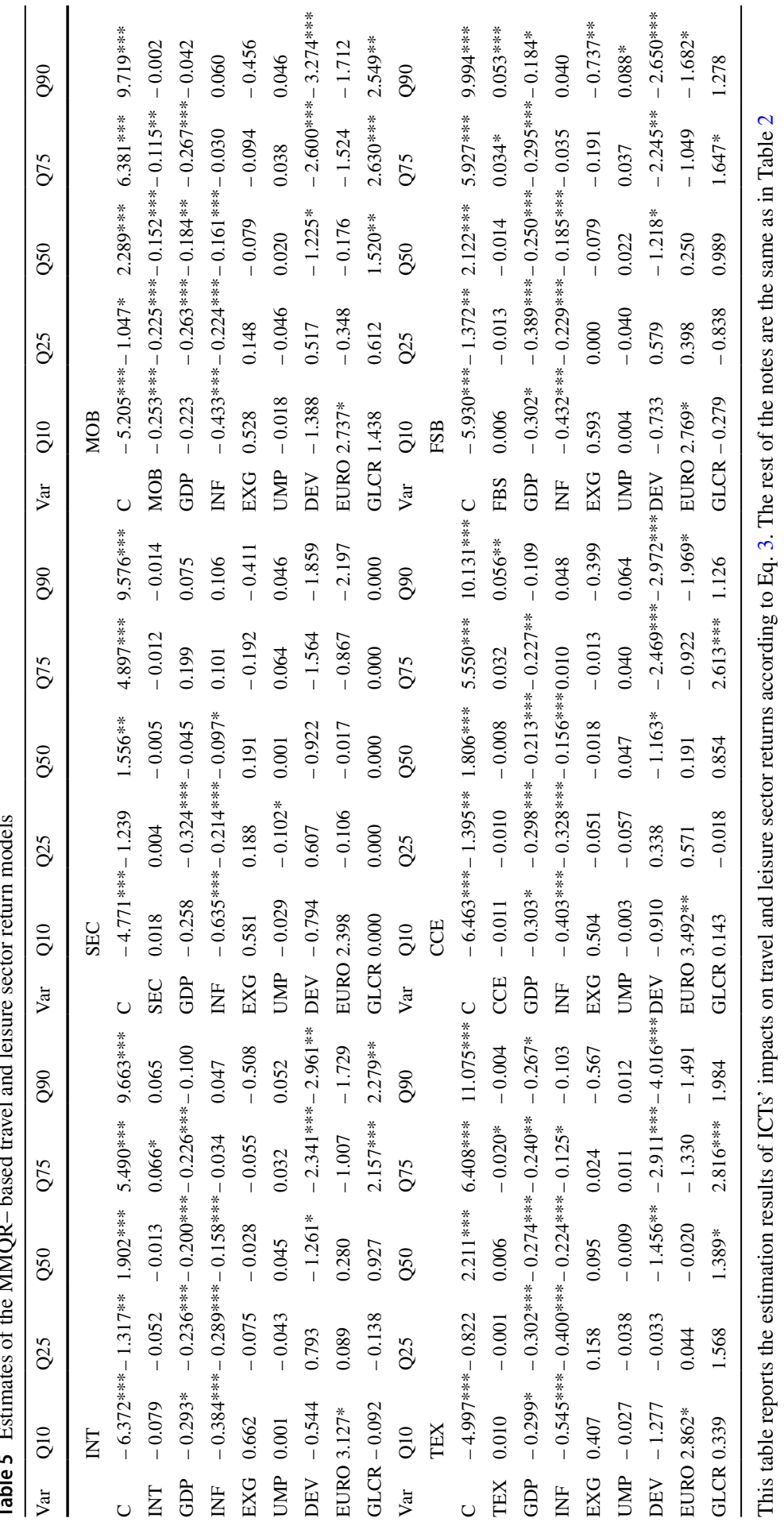



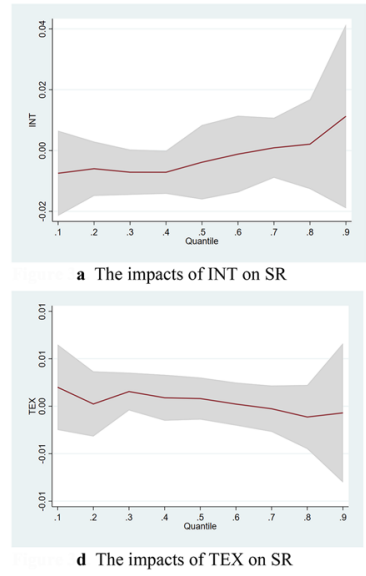

Fig. 3 Panel quantile regression estimates with $95 \%$ confidence intervals for the impacts of the independent variables on travel and leisure sector returns. The same as in Fig. 1

\subsection{Influences of ICTs on travel and leisure sector returns (H3)}

Table 5 presents the estimates of the MMQR-based travel and leisure sector return models by Eq. (3), and in regards to panel quantile regression estimates with $95 \%$ confidence intervals for the impacts of the independent variables on travel and leisure sector returns, Fig. 3 graphically represents the point estimates of the model parameters and displays that the estimated confidence intervals of SEC, TEX, and FBS are smaller, signifying that these variables can work as determinants in identifying SR. INT (CCE) has a substantial and positive influence on SR at the 75th (90th) quantile, and FBS has a salient and positive impact on 75th-90th SR quantiles. Likewise, Kotoua and Ilkan (2017) pinpoint that all types of businesses are supported by Internet marketing, and Internet use has made it easier for e-word of mouth to spread. $\mathrm{Vu}$ (2011) explores the economic effect of ICT and finds that the penetration rate of Internet users has a significant causal effect on economic growth. McDonough (2012) states that FBS increases the market power of the tourist industry. However, MOB has saliently negative impacts on SR at the 10th-75th quantiles, and TEX has a notably negative impact on the 75th quantile. Thus, our finding partially supports H3 that ICTs have important influences on travel and leisure sector returns.

Findings for control variables comprised in the model are also informative. INF is negative and significant at the lower and intermediate quantiles, which matches up with Chen et al. (2005) in that inflation is inversely related to stock returns. The mixed but salient effect of UMP in the highest quantile is in line with Chen et al. (2005) who probe the relations between macroeconomic variables and hotel stock returns and find that the unemployment rate significantly (and negatively) illuminates the movement of hotel stock returns. GDP and EXG show negative impacts on SR. In sum, one probable reason for the insignificance of ICTs on SR might be due to the lag influence in Bayo-Moriones et al. (2013), whereby the effects of 
Table 6 Statistic tests of the equality of slope estimates across various quantiles

\begin{tabular}{llllllll}
\hline Model & Quantile & INT & SEC & MOB & TEX & CCE & FSB \\
\hline AR & Q10vsQ25 & 0.8806 & 0.2915 & $0.0873 \dagger$ & 0.5393 & 0.7718 & 0.2140 \\
& Q10vsQ50 & 0.8352 & 0.6297 & $0.0686 \dagger$ & 0.2219 & 0.5441 & 0.3864 \\
& Q10vsQ75 & 0.4641 & 0.9164 & $0.0644 \dagger$ & 0.1966 & 0.9415 & 0.5964 \\
& Q10vsQ90 & 0.4577 & 0.3542 & $0.0124 \dagger$ & 0.8348 & 0.9799 & 0.5039 \\
& Q25vsQ50 & 0.9063 & 0.7580 & 0.7179 & $0.0589 \dagger$ & 0.2943 & 0.6344 \\
& Q25vsQ75 & 0.2696 & 0.1957 & 0.3012 & $0.0971 \dagger$ & 0.7005 & 0.4602 \\
& Q25vsQ90 & 0.4781 & 0.6286 & $0.0617 \dagger$ & 0.6697 & 0.6199 & $0.0541 \dagger$ \\
& Q50vsQ75 & 0.1850 & 0.2766 & 0.3502 & 0.9465 & 0.2262 & 0.5904 \\
& Q50vsQ90 & 0.4550 & 0.4516 & 0.1011 & 0.2263 & 0.2831 & $0.0552 \dagger$ \\
& Q75vsQ90 & 0.6339 & 0.1371 & 0.2272 & 0.1475 & 0.8544 & 0.1219 \\
& Q10vsQ25 & 0.8732 & 0.9466 & 0.8131 & 0.1296 & 0.5614 & 0.7007 \\
& Q10vsQ50 & 0.9031 & 0.8756 & 0.4052 & 0.3405 & 0.7596 & 0.5123 \\
& Q10vsQ75 & 0.9323 & 0.9803 & 0.3560 & 0.2348 & 0.5659 & 0.6415 \\
& Q10vsQ90 & 0.4372 & 0.8919 & 0.2345 & $0.0540 \dagger$ & 0.8589 & 0.3774
\end{tabular}

Note: $\uparrow$ denotes $\mathrm{P}<0.1$ (two-tailed)

ICT implementation and all the measures of perceived performance are not always instant since the lag effects and lengths vary according to the type of ICT. In the following robustness checks section, we further evaluate the effect of the time-lag effect, geographic area, and non-global crisis sub-period.

\subsection{Robustness checks}

\subsubsection{Equality of slope estimates across different quantiles (H4)}

Table 6 displays the associated $p$-values for the equality of quantile slope coefficients across the various pairs of quantiles. The tests confirm the visual inspection in Table 6 regarding statistic tests of the equality of slope estimates across various quantiles, revealing that $F$-tests reject the null hypothesis of homogeneous coefficients at the $10 \%$ significance level for the MOB-AR, TEX-AR, and FSB-AR pairs of quantiles and indicating that the impacts of the MOB, TEX, and FSB explanatory variables vary across the different parts of the AR; whereas TEX-RV varies across the RV quantile distributions. The findings partially support $\mathrm{H} 4$ that the association between ICTs (i.e., MOB, TEX, and FSB) and tourism development saliently differs at diverse quantiles of the tourism development distribution. 


\subsubsection{Effect of ICTs on subsequent international traveler arrivals}

The findings in Table 3 do not report subjects regarding the lag effect and/or endogeneity. To avoid these problems and include the key variables into the equations, we advance AR by one following period to evade simultaneity in Table 7 regarding estimates of the MMQR-based international traveler arrivals for the $t+1$ period's model. This allows for the influence of any alteration in ICTs to be present in AR. Compared to the ICTs' impact of RV in Tables 3 and 7 for concurrent as well as subsequent periods, we observe the following findings. (1) INT, SEC, and CCE significantly and positively impact AR for the subsequent period at the 90th, 75th, and 25th AR quantiles, respectively. This suggests that INT, SEC, and CCE have non-linear impacts on AR. (2) Consistent with Table 3, MOB has a notably positive impact at higher quantiles, but negative impacts at the lowest quantiles in Table 7, supporting $\mathrm{H} 4$ that the association between ICTs and tourism development differs at diverse quantiles of the development distribution. The subsequent impacts of MOB on AR are also asymmetric. (3) TEX shows no salient impact on AR of the current period, while it shows a saliently negative one in the following period. (4) The salient positive impact of FBS on AR in the current period turns negative in the subsequent period. Whether the disappearing positive impact of FBS from the current to following period is caused by the IT productivity paradox still needs further investigation. (5) The MMQR models of present and subsequent AR have fairly different signs and noteworthy findings. Therefore, we believe that as ICTs improve speedily, their impacts on tourism development should constantly be paid attention to. Additionally, our results show that ICTs have both simultaneous and lagged influences on AR.

\subsubsection{Subsample of the non-global financial crisis period}

As tourism contains discretionary income, it is considered vulnerable to economic uncertainty and volatility (Papatheodorou et al. 2010; Lee et al. 2020). Because international tourism statistics showed negative growth in 2008, it was anticipated that they would turn worse during 2009 (Papatheodorou et al. 2010). Therefore, we eliminate the influence of the 2008 global financial crisis and set 2006-2007 and 2010-2017 as non-global financial crisis sub-periods to perform MMQR equations in Table 8 in regard to the estimates of international traveler arrivals. The findings in Table 8 reveal similar remarkably positive influences of SEC, MOB, and FBS on AR as in Table 3. Therefore, compared to the full period findings and non-global financial crisis period, the impacts of SEC, MOB, and FBS on AR are quite consistent.

\subsubsection{Subsample of developing nations}

Eugenio-Martín et al. (2004) discover that the nexus for the number of traveler arrivals and economic development occurs in developing nations, ${ }^{4}$ but not in developed nations. We explore whether ICT factors have diverse influences on dependent

\footnotetext{
4 Data source: Table $\mathrm{C}$ developing economies by region of World Economic Situation and Prospects from the United Nations. We present this data source from: 2014wesp_country_classification.pdf.
} 


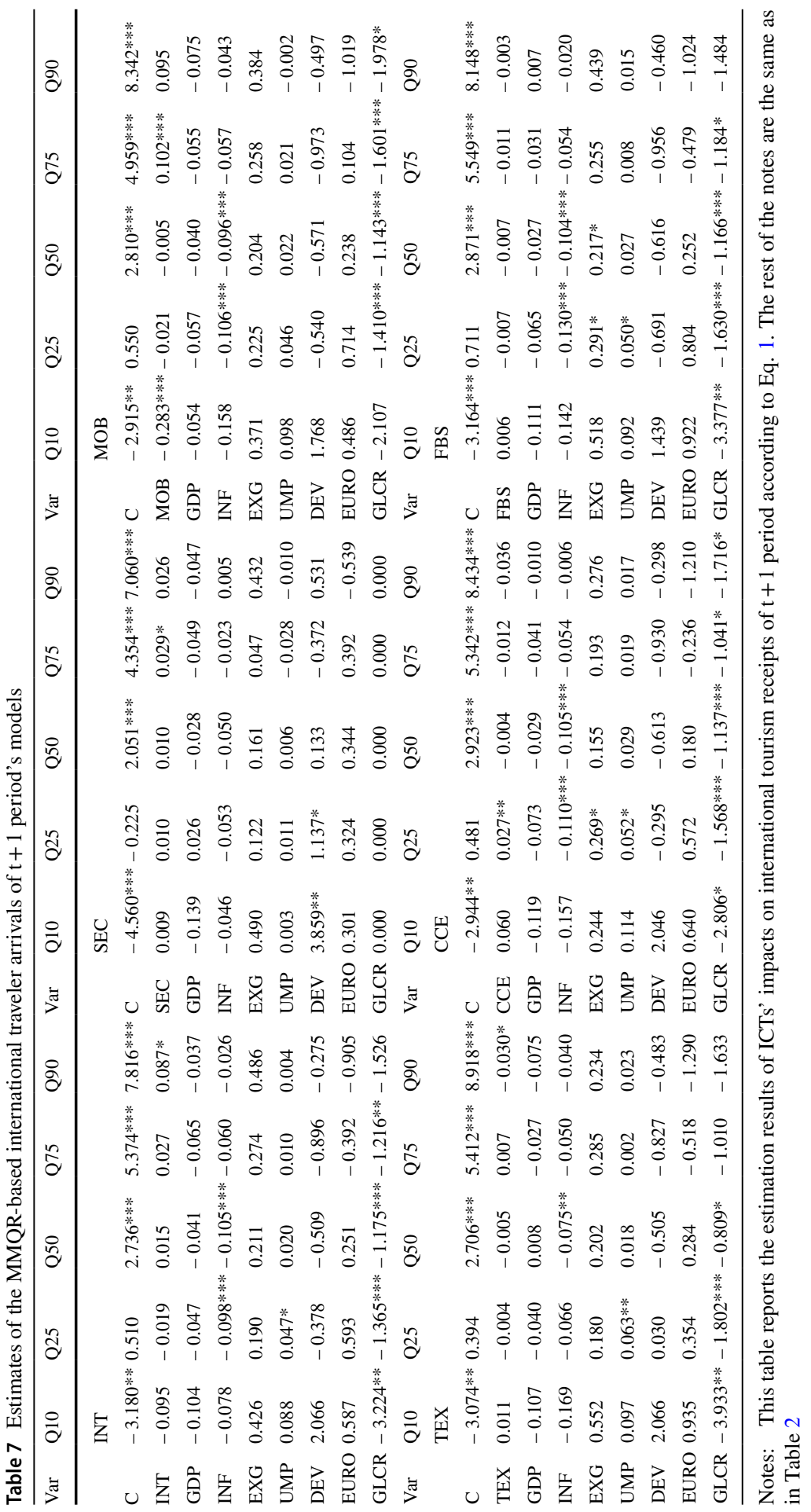




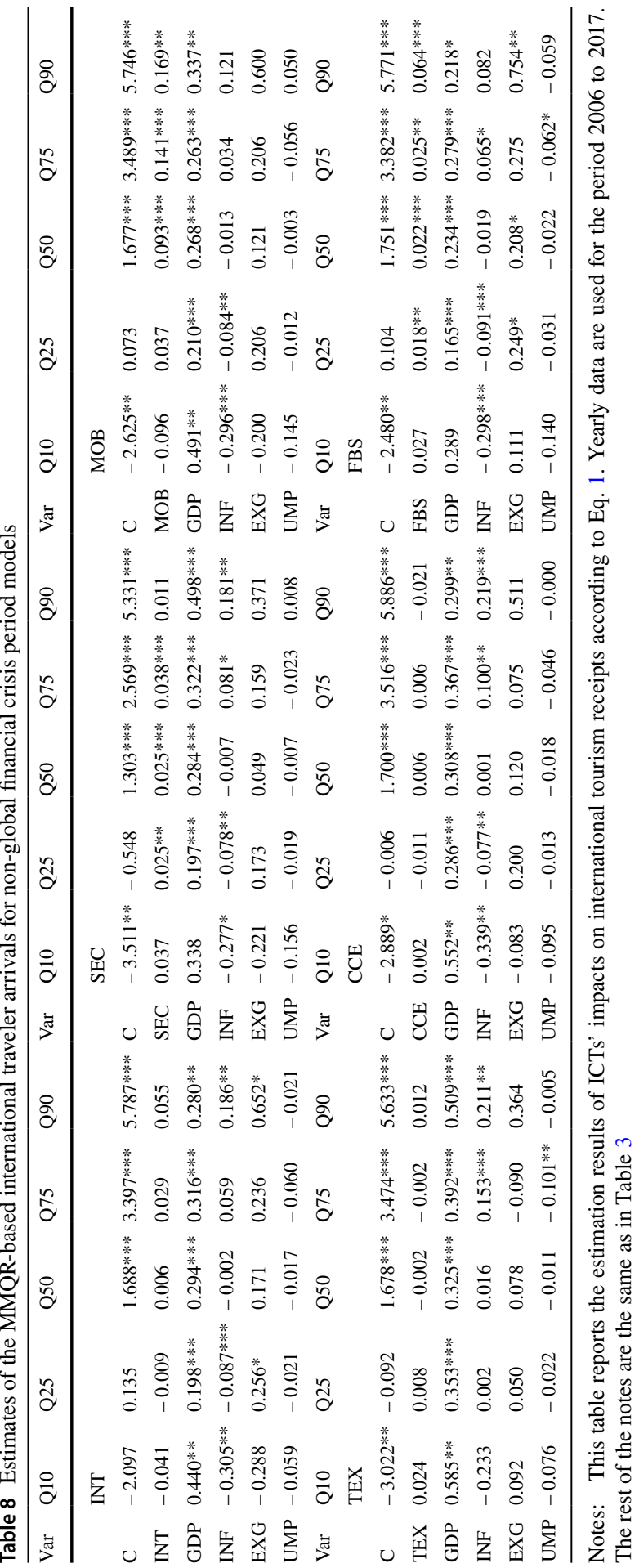


variables using 79 developing nations as the subsample and present the empirical findings. ${ }^{5}$ Consistent with Table 3 , MOB, SEC, and FBS still show significantly positive impacts at several AR quantiles, and their positive impacts are more salient on developing countries' AR. We also observe a notably positive influence of TEX on AR for developing countries' lower AR quantile, while INT and CCE show no salient impact on AR, which is consistent with the findings in Table 3. Our findings also concur with Bhat and Shah (2014) that ICT deployment is especially important for emerging areas. The findings of the developing nation subgroup are similar to those of the full sample.

\subsubsection{Subsample of European nations}

According to International Tourism Highlights (2019) from the World Tourism Organization, Europe accounts for $50 \%$ of global international arrivals and receives almost $40 \%$ of international tourism revenues, followed by Asia and the Pacific. Because the relationship between tourism receipt and GDP differs with geographic regions (Çağlayan et al. 2012), we employ the biggest sample region of 38 European nations as a subgroup to assess the robustness of ICT factors in specific region samples in Table 9. Consistent with Table 3, SEC and MOB display considerably positive effects on AR, signifying the upgrade in influence of SEC and $\mathrm{MOB}$ on AR in European nations. However, FBS shows a negative impact on AR. Additionally, TEX and CCE show saliently negative impacts on AR in Table 9. INT presents asymmetric impacts on AR from positive in higher quantiles to negative in lower quantiles for European nations. The findings of the European nation subgroup are different from those of the entire sample, but are consistent with Çağlayan et al. (2012) in that the nexus of economic factor and tourism receipt presents different geographic area features. Thus, we further enlarge the findings of Çağlayan et al. (2012) to the ICT-tourism nexus. Except for the European nation results, we discover no other notable dissimilarities between the main findings and other robustness tests, indicating that ICTs non-linearly impact AR, $\mathrm{RV}$, and SR.

We condense the results in Table 12 summary of the empirical results. In short, there are saliently positive impacts of SEC, MOB, and FBS, supporting H1 in that ICTs have positive and substantial impacts on international traveler arrivals, especially for several specific AR quantiles. However, MOB (TEX) has negative impacts on SR at the 10th to 75th (75th) quantiles. Likewise, CCE (MOB) has significantly negative impacts on RV for all (25th-50th) quantiles on tourism receipts. Therefore, the findings support $\mathrm{H} 2(\mathrm{H} 3)$ in that ICTs have substantial impacts on international tourism receipts (travel and leisure sector returns) at specific quantiles.

We infer the negative impacts of CCE and MOB (TEX and MOB) on RV (SR) due to the IT productivity paradox, specifying the possibility of a time-lag effect, peer effect, and ICT commoditization. Moreover, Chen et al. (2012) indicate that

\footnotetext{
5 Due to space limitation and a reviewer's suggestion, we omit the table of the MMQR-based international traveler arrivals for developing nations.
} 


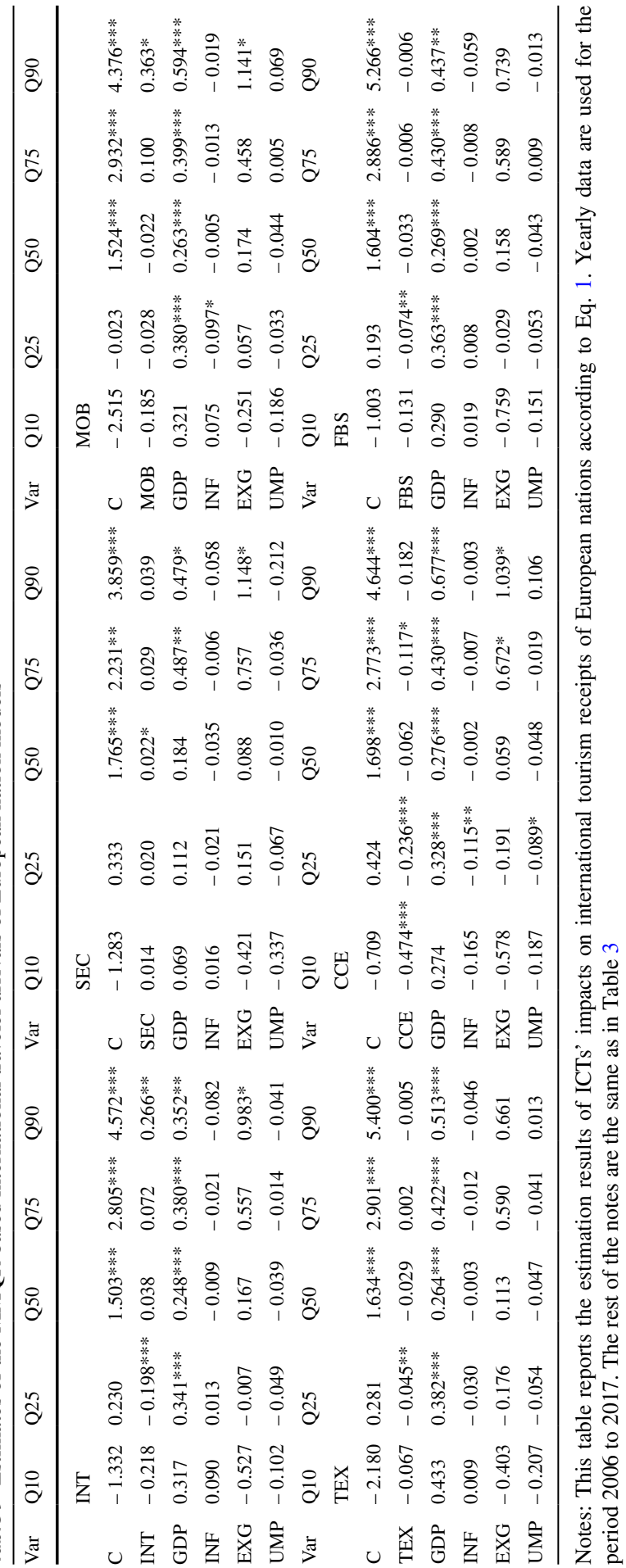


economic variables like the discount rate, unemployment rate, and oil price significantly cause Japanese hotel stock returns. Compared with tourism receipts, tourism arrivals can be more directly and immediately used to estimate tourism development. Thus, H1-H3 are supported. We further observe that the influences of ICTs on AR, RV, and SR are salient at some of the quantiles, while not at others. For instance, FBS saliently impacts RV (SR) at the 90th (75th-90th) quantile(s), while TEX impacts RV (SR) at the 90th (75th) quantile. Therefore, H4 is supported, in that the association between ICTs and tourism development saliently differs at diverse quantiles of the tourism distribution.

\section{Implication and discussion}

Expanding from the prior studies of Andrianaivo and Kpodar (2011), Adeola and Evans (2020), Kumar and Kumar (2020), and Choudhary et al. (2020), our research explores more comprehensively ICTs and tourism variables, provides global evidence, and considers the different ICTs' impacts across varying tourism quantiles. Our positive MOB finding is consistent with Choudhary et al. (2020) in that mobile cellular subscriptions have a positive effect on tourism development. Moreover, Rajan et al. (2016) address that an increase in the number of secure Internet servers results in an increase in the number of tourism arrivals, which matches our findings on salient and positive SEC impacts on AR. Therefore, taking ICTs into account helps tourism participants to realize the ICT determinants of AR. Our finding is consistent with Adeola and Evans (2020) who find when ICT and infrastructure increase in African nations that the level of traveler arrivals also increases. Our findings are also consistent with Bhat and Shah (2014), whereby ICT deployment is especially important for emerging areas. However, contradictive to the related literature that shows ICTs' positive impacts, our findings reveal ICTs' negative impacts, which are consistent with the saying of the IT productivity paradox.

Given the importance of ICTs on AR, RV, and SR, policymakers and/or travel and leisure managers need to consider how to build up ICT infrastructure and applications to develop tourism. Our results are vital to understanding tourism development under the sector's greatly competitive markets globally. Several implications can be obtained from the empirical findings of this study. First, regarding to increase AR, secure Internet servers, mobile cellular subscriptions, and fixed broadband subscriptions have saliently positive impacts on international traveler arrivals, suggesting that nations and tourism participants that want to attract international travelers should improve these three ICTs. In other words, nations with less international arrivals are positively sensitive to the set-up of secure Internet servers, mobile cellular subscriptions, and fixed broadband subscriptions. The higher the levels of SEC, $\mathrm{MOB}$, and FBS in the nation, the higher the number of AR. This finding infers that SEC, MOB, and FBS can enable tourism destination nations to increase the online presence (i.e., visibility on the Internet and collaboration with related sectors) necessary to be competitive in the global tourism market. This also advocates that as these three ICT infrastructures improve across the nations, the keener will be travelers to visit and realize the opportunities and endowments embedded in the destination 
country. On the contrary, mobile cellular subscriptions, the percentage of individuals using the Internet, high-technology exports, and communications as well as computer do no notably improve on traveler number.

Second, regarding the negative impacts of ICTs, MOB negatively affects SR (RV) at the 10th to 75 th (25th-50th) quantiles, plus TEX (CCE) negatively impacts SR (RV) at the 75th (all) quantile(s). Interestingly, we also notice the positive INT and CCS effects (TEX and FBS effects) on SR (RV) at higher quantile, revealing the diverse features among ICT. Practically, nations with the highest tourism receipts (tourism stock returns) can increase high-technology exports and fixed broadband subscriptions (individual using Internet, communications as well as computer, and fixed broadband subscriptions) to further help raise tourism receipts (tourism stock returns). Nations with lower tourism receipts should not target to increase mobile cellular subscriptions, communication, and computer technologies. Thus, any ICT investment should consider their level of tourism development as well as the target they want to improve in order to avoid any downside risk. Moreover, secure Internet servers (individuals using the Internet) does not affect RV and SR (RV), implying the higher cost of implementing secure Internet servers and individuals using the Internet than revenues.

Third, our research findings allow academic research in related fields to consider the non-linear impacts of ICTs in tourism development. In other words, our findings identify that if one ignores the possibility that the ICTs-tourism nexus could be non-linear, then the results from a linear model could often cause bias due to using a false valuation method. Our evidence confirms that ICTs non-linearly influence AR, $\mathrm{RV}$, and SR across different quantiles, implying countries establishing ICTs should consider different tourism development quantiles to apply different types of ICT.

Fourth, we address the asymmetric impacts of ICTs at different quantiles of tourism development. In other words, mobile cellular subscriptions have a negative impact from the lowest quantile and a positive impact at higher quantiles on the subsequent period's AR. Additionally, the percentage of Internet usage has a negative impact from the lowest quantile and a positive impact at higher quantiles for European countries. This asymmetry has important implications for the growth strategies of developing tourism (Faber and Gaubert 2019) and whether the development of ICTs should be prioritized. Therefore, for nations at varying AR quantiles, different regions, different periods, and different ICTs have varying impacts on tourism development. ICTs can thus serve as tourism development determinants especially for the non-global financial period and for developing nations. Furthermore, instead of upgrading all kinds of ICTs, priority should be given to the tourism development quartile and then toward investing in specific ICTs. Our findings have important implications across different tourism factors' quantiles for improving this industry, and this can help management strategies during both downside and upside conditions.

Fifth and finally, our research findings validate two theories. First, our findings of ICTs' positive impacts show that countries with different tourism development levels should consider their diverse influence, which corresponds to the resource-based view theory of Wernerfelt (1995) in that a firm should consider its endowments to ensure that it always can competent with the best in whatever market it chooses to 
compete. For example, we suggest tourism managers and policy makers of countries with higher SR (RV) could improve their countries' INT, CCE, and FBS (TEX and FBS) so as to raise their travel and leisure sector returns (tourism receipts). Our research expands the resource-based view from firm management to country tourism and ICT related fields. However, SEC, MOB, and FBS positively influence tourist arrivals at most of the quantiles, suggesting that tourism managers and policy makers can apply and improve more SEC, MOB, and FBS related technologies in order to increase international tourism arrivals.

Second, regarding our findings of ICTs' negative impacts, MOB negatively affects SR (RV) at the 10th to 75th (25th-50th) quantiles, while TEX (CCE) negatively impacts SR (RV) at the 75th (all) quantile(s). Our research observes the condition of the IT productivity paradox in the tourism field due to some salient negative and insignificant impacts of ICTs in RV. The reasons for this negative impact might relate to the time-lag effect, peer effect and/or commoditization (i.e., ICTs are like railroads and electricity, as they are necessities and widely used). Our research findings allow academic research in related fields to consider the non-linear impacts of ICTs in tourism development. In other words, our findings identify that if one ignores the possibility that the ICTs-tourism nexus could be non-linear, then the results from a linear model could often cause bias due to using a false valuation method.

\section{Conclusion}

This research complements the literature on the relationships between destination nations' levels of ICTs and tourism development by paying distinctive attention to the distributions of international traveler arrivals, international tourism receipts, and travel and leisure sector returns via yearly data of 118 nations for the period 2006-2017. The main goal is to probe international evidence regarding whether ICTs influence tourism development across the conditional distribution of tourism elements. For this purpose, we use a new quantile regression approach proposed by Machado and Silva (2019). Additionally, we consider that the correlations might vary during a non-global financial crisis period, by geographic area, and under different economic development states.

Our results suggest that secure Internet servers, mobile cellular subscriptions, and fixed broadband subscriptions have positive impacts on international traveler arrivals, while mobile cellular subscriptions and communication, computer notably and negatively affect tourism receipts for nations with the highest tourism receipts. Mobile cellular subscriptions and high-technology exports (Internet usage, communication, computer, and fixed broadband subscriptions) negatively (positively) impact travel and leisure sector returns at different return quantiles. Thus, our findings support that ICTs of the host nation positively determine traveler arrivals, tourism receipts, and sector returns.

The negative impacts of ICTs are consistent with the IT productivity paradox. The reason for the IT productivity paradox can be explained by the peer effect, 
time-lagging effect, and commoditization. Specifically, Gangopadhyay and Nilakantan (2021) explore the bank industry and address that although IT adoption can enhance firm productivity, resource use efficiency, and service quality through strengthening organizational capabilities, a proper assessment of the costs and benefits of any new technology may be difficult for potential users, because IT productivity paradox has previously overlooked the influence of peer firms. Hwang et al. (2015) find that computer and Internet usage do not relate to enhancing a firm's competitive advantage, since they are now commoditized, much like railroads and electricity (Carr 2003). In other words, computers and Internet usage are not influenced by either product/service performance or business process performance (Hwang et al. 2015). Toy (2021) addresses in the short run that artificial intelligence implementation does not appear to affect overall productivity statistics due to the time-lag explanation presented by Brynjolffson et al. (2019).

There is salient evidence showing how ICTs asymmetrically and non-linearly influence tourism development across different quantiles. Further test results disclose that the relationships between ICTs and tourism development are robust after considering non-global financial sub-periods, endogeneity problems, and economic development conditions. However, the positive impact of fixed broadband subscriptions is insignificant for the European nation group, implying the existence of a geographic region difference in the ICTs-tourism nexus.

We also study whether the impacts of macroeconomic factors correlate with traveler arrivals, tourism receipts, and travel and leisure sector returns. We discover that GDP, real exchange rate, inflation, and unemployment are considerably associated with different quantiles of traveler arrivals, tourism receipts, and sector returns. The GDP per capita growth rate notably and positive correlates with traveler arrivals, while negatively correlates with tourism receipts and sector returns. Unemployment (inflation) is asymmetric and noticeable related with travel and leisure sector returns (traveler arrivals). The results are consistent with the existing literature that there is an asymmetric link between economic factors and tourism (Meo et al. 2018). Baur and McDermott (2010) define safe-haven assets as those can help investors build a portfolio that mitigates any downside market risk. Interestingly, we find salient positive impacts of the global financial crisis on sector returns at intermediate and higher return quantiles, suggesting countries with intermediate and higher travel and leisure sector returns can be a safe-haven for assets during the global financial crisis.

Identifying the ICTs and tourism nexus has been a crucial subject in the tourism arena, yet undeniably we merely probe at their association among six ICTs. These are three limitations of this study. First, because we focus the discussion on six kinds of ICTs, there are other new ICT issues we have omitted, such as artificial intelligence (AI) and robotics, which could enhance our understanding of advanced technology's effects on tourism. Second, the COVID-19 pandemic has resulted in serious ongoing challenges to the travel and tourism sector, but we do not consider the pandemic's impacts on this sector. It would be interesting for studies to examine the possible benefits of new ICTs on the travel and tourism sector during serous 
pandemic periods. Third, this study mainly covers the non-linear effects of ICT on tourism development across different quantiles, and omits the causal relationships between ICT and tourism development. We leave these three topics for future endeavors.

\section{Appendix}

See Tables 10, 11, 12; Fig. 4. 
Table 10 Main variable list

\begin{tabular}{lc}
\hline Variable & Definition and source \\
\hline $\begin{array}{l}\text { Dependent variables } \\
\text { AR }\end{array}$ & Log difference of international inbound travelers are the \\
& yearly number of travelers who travel to a nation other \\
& than that in which they have their usual residence (from \\
& WDI of World Bank database) \\
Log difference of international tourism receipts (\% of total \\
RV & exports) calculated as a ratio to exports of goods and ser- \\
& vices; international tourism receipts are expenditures by \\
& international inbound travelers, comprising payments to \\
& national carriers for international transport and any other \\
& pre-payments made for goods or services received in the \\
& destination nation (from WDI of World Bank database) \\
& Yearly travel and leisure sector returns are estimated by \\
& $\left(\mathrm{P}_{\mathrm{t}}-\mathrm{P}_{\mathrm{t}-1}\right) / \mathrm{P}_{\mathrm{t}-1} ; \mathrm{P}_{\mathrm{t}}$ is yearly sector closing prices (from \\
DataStream database)
\end{tabular}

\section{Independent variables}

Six ICT variables are from WDI

INT

SEC

MOB

TEX

CCE

FBS

\section{Control variables}

Macroeconomic factors are from WDI

\section{EXG}

GDP

INF

UMP

DEV

EURO

GLCR

Individuals using the Internet, \% of population

Secure Internet servers, per 1 million people

Mobile cellular subscriptions, per 100 people

High-technology exports, \% of manufactured exports

Communications, computer, etc., $\%$ of service exports

Fixed broadband subscriptions, per 100 people

Real exchange rate $=($ destination country's official exchange rate*US CPI)/destination country's CPI

GDP per capita growth, annual \%

Inflation, consumer prices, annual \%

Unemployment, total \% of total labor force

Developed country, equals 1 if the country is developed and 0 otherwise

European country equals 1 if the country is in Europe and 0 otherwise

Global crisis, equals 1 if the period is during the global financial crisis (2008-2009) and 0 otherwise (Ntim et al., 2013)

Notes: All the variables are in log difference form, except for SR, and GDP, INF, and EXG. EXG is in $\log$ form. Except for the travel and leisure stock prices of 118 countries, all data are from the World Development Indicators (WDI) by the World Bank database, which is the most comprehensive international database 
Table 11 Sample nation list

\begin{tabular}{llllll}
\hline Afghanistan\# & Chad\# & Greece & Latvia & Panama\# & Sweden \\
Albania\# & Chile & Guatemala\# & Lebanon\# & Paraguay\# & Switzerland \\
Argentina\# & China\# & Haiti\# & Lithuania & Peru\# & Tajikistan\# \\
Armenia\# & Colombia\# & Honduras\# & Madagascar\# & Philippines\# & Tanzania\# \\
Australia & Congo\# & Hong Kong & Malawi\# & Poland & Thailand\# \\
Austria & Costa Rica\# & Hungary & Malaysia\# & Portugal & Turkey\# \\
Azerbaijan\# & Croatia & Iceland & Mali\# & Romania & Uganda\# \\
Bangladesh\# & Cyprus & India\# & Mauritania\# & Russia\# & Ukraine\# \\
Belarus\# & Czech & Indonesia\# & Mexico\# & Rwanda\# & UAE\# \\
Belgium & Denmark & Iran\# & Moldova\# & Saudi Arabia\# & UK \\
Benin\# & Dominican\# & Iraq\# & Mongolia\# & Senegal\# & U.S \\
Bolivia\# & Ecuador\# & Ireland & Montenegro\# & Serbia\# & Uruguay\# \\
Bosnia and Herzegovina\# & Egypt\# & Israel & Nepal\# & Sierra Leone\# & Uzbekistan\# \\
Botswana\# & El Salvador\# & Italy & Netherlands & Singapore & Venezuela\# \\
Brazil\# & Estonia & Japan & New Zealand & Slovakia & Vietnam\# \\
Bulgaria & Finland & Jordan\# & Nicaragua\# & Slovenia & Yemen\# \\
Burkina Faso\# & France & Kazakhstan\# & Niger\# & South Africa\# & Zambia\# \\
Cambodia\# & Georgia\# & Kenya\# & Nigeria\# & South Korea & Zimbabwe\# \\
Cameroon\# & Germany & Kuwait\# & Norway & Spain & \\
Canada & Ghana\# & Kyrgyzstan\# & Pakistan\# & Sri Lanka\# & \\
\hline & & & & &
\end{tabular}

Notes: We gather the nations that have tourism relevant data in the World Bank database, and the above 118 nations are utilized in this study. The bold nations are in Europe. \# signifies developing countries

Table 12 Summary of the empirical results

\begin{tabular}{|c|c|c|c|c|c|c|c|}
\hline No & Hypothesis & INT & SEC & MOB & TEX & $\mathrm{CCE}$ & FBS \\
\hline $\mathrm{H} 1$ & $\mathrm{ICT} \rightarrow \mathrm{AR}$ & & $25,50,75$ & $25,50,75,90$ & & & $10,25,50,75,90$ \\
\hline $\mathrm{H} 2$ & $\mathrm{ICT} \rightarrow \mathrm{RV}$ & & & $-25,-50$ & 90 & $\begin{array}{l}-10,-25,- \\
50,-75,- \\
90\end{array}$ & 90 \\
\hline H3 & $\mathrm{ICT} \rightarrow \mathrm{SR}$ & 75 & & $-10,-25,-50,-75$ & -75 & 90 & 75,90 \\
\hline $\mathrm{H} 4$ & $\begin{array}{l}\text { ICT (non- linear } \\
\text { impact) } \rightarrow \text { Tour- } \\
\text { ism }\end{array}$ & Accept & & & & & \\
\hline
\end{tabular}

Notes: ICT (information and communication technology), SR (travel and leisure sector returns), RV (international tourism receipts as \% of total exports), and AR (number of international tourism arrivals). $10,25,50,75$, and 90 saliently represent in these quantiles. "-" denotes a negative impact; otherwise it is positive 
Fig. 4 Research Framework. MMQR analysis is a non-linear model and allows for fixed effects

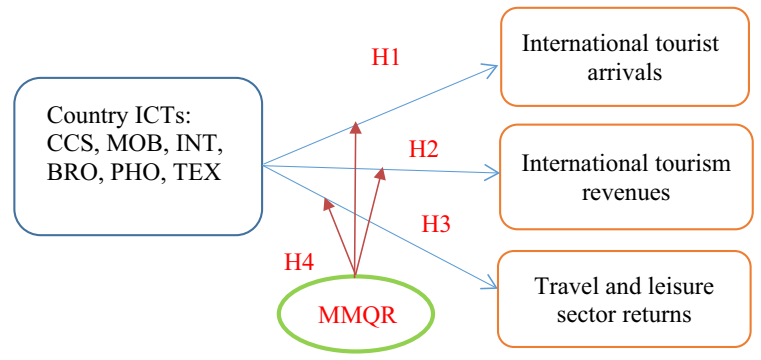

Acknowledgements The authors are grateful for the insightful comments and suggestions received from the Editor-in-chief Dr. Zheng Xiang and three anonymous referees on an earlier of this paper. This work was supported by National Taichung University of Science and Technology in Taiwan.

Funding Chien-Chiang Lee is grateful to the Social Science Foundation of Jiangxi Province of China for financial support through Grant No: 21JL02.

\section{Declarations}

Conflict of interest The authors declare no potential conflicts of interest with respect to the research, authorship, and/or publication of this article.

\section{References}

Ab Wahab NY, Mohamad M, Yusuff YZ, Musa R (2020) The importance of ICT adoption in manufacturing sector: an empirical evidence on SME business performance. Int J Supply Chain Manag 9(2):268-272

Abrhám J, Wang J (2017) Novel trends on using ICTS in the modern tourism industry. Czech J Soc Sci Bus Econ 6(1):37-43

Adeola O, Evans O (2020) ICT, infrastructure, and tourism development in Africa. Tour Econ 26(1):97-114

Akal M (2004) Forecasting Turkey's tourism revenues by ARMAX model. Tour Manag 25(5):565-580

Akron S, Demir E, Díez-Esteban JM, García-Gómez CD (2020) Economic policy uncertainty and corporate investment: evidence from the US hospitality industry. Tour Manag 77:104019

Allen F, Gu X, Kowalewski O (2012) Financial crisis, structure and reform. J Bank Financ 36(11):2960-2973

Al-Mulali U, Solarin SA, Andargoli AE, Gholipour HF (2020) Digital adoption and its impact on tourism arrivals and receipts. Anatolia. https://doi.org/10.1080/13032917.2020.1856692

Andrianaivo, M., \& Kpodar, K. (2011). ICT, financial inclusion, and growth: Evidence from African countries. IMF Working Paper No. 11/73. https://www.uneca.org/sites/default/files/uploadeddocuments/AEC/2010/Papers/session_i.2.1_1._ict_financial_inclusion_and_growth.pdf

Aramendia-Muneta ME, Ollo López A (2013) ICT impact on tourism industry. Int J Manag Case 15(2):87-98

Balli HO, Tsui WHK, Balli F (2019) Modelling the volatility of international visitor arrivals to New Zealand. J Air Transp Manag 75:204-214

Bayo-Moriones A, Billón M, Lera-López F (2013) Perceived performance effects of ICT in manufacturing SMEs. Ind Manag Data Syst 113(1):117-135

Bethapudi A (2013) The role of ICT in tourism industry. J Appl Econ Bus 1(4):67-79

Bhat SA, Shah MA (2014) Diffusion of internet technology in the tourism sector: an empirical study. J Transnat Manag 19(2):152-164 
Binder M, Coad A (2011) From average Joe's happiness to Miserable Jane and Cheerful John: using quantile regressions to analyze the full subjective well-being distribution. J Econ Behav Org 79(3):275-290

Bizirgianni I, Dionysopoulou P (2013) The influence of tourist trends of youth tourism through social media (SM) \& information and communication technologies (ICTs). Procedia Soc Behav Sci 73:652-660

Bretschger L, Kappel V, Werner T (2012) Market concentration and the likelihood of financial crises. J Bank Financ 36(12):3336-3345

Brynjolfsson E (1993) The productivity paradox of information technology. Commun ACM 36(12):6677. https://doi.org/10.1145/163298.163309

Brynjolfsson E, Rock D, Syverson C (2019) 1. Artificial intelligence and the modern productivity paradox: a clash of expectations and statistics (pp. 23-60). University of Chicago Press.

Buhalis D, Law R (2008) Progress in information technology and tourism management: 20 years on and 10 years after the Internet - The state of eTourism research. Tour Manag 29(4):609-623

Çağlayan E, Sak N, Karymshakov K (2012) Relationship between tourism and economic growth: a panel Granger causality approach. Asian Econ Financ Rev 2(5):591

Canay IA (2011) A simple approach to quantile regression for panel data. Economet J 14(3):368-386

Carr NG (2003) IT doesn't matter. Harvard Bus Rev pp 41-49

Castro-Nuño M, Molina-Toucedo JA, Pablo-Romero MP (2013) Tourism and GDP: a meta-analysis of panel data studies. J Travel Res 52(6):745-758

Chen MH (2007) Macro and non-macro explanatory factors of Chinese hotel stock returns. Int J Hosp Manag 26(4):991-1004

Chen MH (2011) The response of hotel performance to international tourism development and crisis events. Int J Hosp Manag 30(1):200-212

Chen MH, Kim WG, Kim HJ (2005) The impact of macroeconomic and non-macroeconomic forces on hotel stock returns. Int J Hosp Manag 24(2):243-258

Chen PF, Lin CW, Lee CC (2019) Financial crises, globalization, and insurer performance: Some international evidence. N Am J Econ Financ 48:835-856

Chinn MD, Fairlie RW (2007) The determinants of the global digital divide: a cross-country analysis of computer and internet penetration. Oxf Econ Pap 59(1):16-44

Chinn MD, Fairlie RW (2010) ICT use in the developing world: an analysis of differences in computer and internet penetration. Rev Int Econ 18(1):153-167

Chiu YB, Yeh LT (2017) The threshold effects of the tourism-led growth hypothesis: evidence from a cross-sectional model. J Travel Res 56(5):625-637

Choudhary SA, Khan MA, Sheikh AZ, Jabor MK, bin Nordin MS, Nassani AA, Zaman K (2020) Role of information and communication technologies on the war against terrorism and on the development of tourism: evidence from a panel of 28 countries. Technology in Society, 101296

Demir E, Alıcı ZA, Lau CK, M. (2017) Macro explanatory factors of Turkish tourism companies' stock returns. Asia Pac J Tour Res 22(4):370-380

Divino JA, McAleer M (2010) Modelling and forecasting daily international mass tourism to Peru. Tour Manag 31(6):846-854

Elheddad M, Djellouli N, Tiwari AK, Hammoudeh S (2020) The relationship between energy consumption and fiscal decentralization and the importance of urbanization: evidence from Chinese provinces. J Environ Manag 264:110474

Eugenio-Martin JL, Martín Morales N, Scarpa R (2004) Tourism and economic growth in Latin American countries: A panel data approach. SSRN Electron J. www.ssrn.com, working paper. https://doi. org/10.2139/ssrn.504482

Faber B, Gaubert C (2019) Tourism and economic development: evidence from Mexico's coastline. Am Econ Rev 109(6):2245-2293

Fama EF (1981) Stock returns, real activity, inflation, and money. Am Econ Rev 71(4):545-565

Fernández JAS, Azevedo PS, Martín JMM, Martín JAR (2020) Determinants of tourism destination competitiveness in the countries most visited by international tourists: proposal of a synthetic index. Tour Manag Perspect 33:100582

Feshari M (2017) The role of ICT indices in tourism Demand of Iran (The FMOLS Co-integrating Approach). Iranian J Econ Stud 5(2):209-221

Gangopadhyay P, Nilakantan R (2021) Peer effects and social learning in banks' investments in information technology. Int Rev Econ Financ 75:456-463 
Ghartey EE (2013) Effects of tourism, economic growth, real exchange rate, structural changes and hurricanes in Jamaica. Tour Econ 19(4):919-942

Gokovali U (2010) Contribution of tourism to economic growth in Turkey. Anatolia 21(1):139-153

Gooroochurn N, Sugiyarto G (2005) Competitiveness indicators in the travel and tourism industry. Tour Econ 11(1):25-43

Grace J, Kenny C, Qiang CZW (2003) Information and communication technologies and broad-based development: a partial review of the evidence. The World Bank

Guo Y, You W, Lee CC (2020) $\mathrm{CO}_{2}$ emissions, income inequality, and country risk: some international evidence. Environ Sci Pollut Res. https://doi.org/10.1007/s11356-020-09501-w

Heckman JJ, Smith J, Clements N (1997) Making the most out of programme evaluations and social experiments: accounting for heterogeneity in programme impacts. Rev Econ Stud 64(4):487-535

Hwang JS, Kim S, Lee H (2015) Breaking the myths of the IT productivity paradox. KSII Trans Int Inf Syst (TIIS) 9(1):466-482

Inchausti-Sintes F (2015) Tourism: Economic growth, employment and Dutch disease. Ann Tour Res 54:172-189

Januszewska M, Jaremen DE, Nawrocka E (2015) The effects of the use of ICT by tourism enterprises. Zeszyty Naukowe Uniwersytetu Szczecińskiego. Sci J Serv Manag 16:65-73

Ketteni E, Mamuneas TP, Stengos T (2007) Nonlinearities in economic growth: a semiparametric approach applied to information technology data. J Macroecon 29(3):555-568

Khan HUR, Zaman K, Shoukry AM, Sharkawy MA, Gani S, Sasmoko, ... \& Hishan, S. S. (2019) Tourism logistics management through financial and regulatory measures: evidence from a panel of countries. Asia Pac J Tour Res 24(5):443-458

Koenker R (2004) Quantile regression for longitudinal data. J Multivar Anal 91(1):74-89

Koenker R, Hallock KF (2001) Quantile regression. J Econ Perspect 15(4):143-156

Kotoua S, Ilkan M (2017) Tourism destination marketing and information technology in Ghana. J Destin Mark Manag 6(2):127-135

Kpodar K, Andrianaivo M (2011) ICT, financial inclusion, and growth evidence from African countries (No. 11-73). International Monetary Fund

Kumar RR, Kumar R (2012) Exploring the nexus between information and communications technology, tourism and growth in Fiji. Tour Econ 18(2):359-371

Kumar N, Kumar RR (2020) Relationship between ICT and international tourism demand: a study of major tourist destinations. Tour Econ 26(6):908-925

Kumar RR, Stauvermann PJ, Kumar N, Shahzad SJH (2019) Exploring the effect of ICT and tourism on economic growth: a study of Israel. Econ Chang Restruct 52(3):221-254

Laeven L, Valencia F (2012) Systemic banking crises database: an update. SSRN, working paper

Lancaster T (2002) Orthogonal parameters and panel data. Rev Econ Stud 69(3):647-666

Law R, Leung R, Buhalis D (2009) Information technology applications in hospitality and tourism: a review of publications from 2005 to 2007. J Travel Tour Mark 26(5-6):599-623

Lee JW, Brahmasrene T (2013) Investigating the influence of tourism on economic growth and carbon emissions: evidence from panel analysis of the European Union. Tour Manag 38:69-76

Lee CC, Chang CP (2008) Tourism development and economic growth: a closer look at panels. Tour Manag 29(1):180-192

Lee CC, Olasehinde-Williams G, Akadiri SS (2020) Geopolitical risk and tourism: evidence from dynamic heterogeneous panel models. Int J Tour Res 23:26-38. https://doi.org/10.1002/jtr.2389

Lee CC, Wang CW, Ho SJ (2021) The impact of natural disaster on energy consumption: international evidence. Energy Econ 97:105021. https://doi.org/10.1016/j.eneco.2020.105021

Lee CC, Chen MP (2020) Do country risks matter for tourism development? International evidence. J Travel Res. forthcoming. https://doi.org/10.1177/0047287520954539

Lv Z, Xu T (2017) A panel data quantile regression analysis of the impact of corruption on tourism. Curr Issue Tour 20(6):603-616

Machado JA, Silva JM (2019) Quantiles via moments. J Econ 213(1):145-173

Mavri M, Angelis V (2009) Forecasting the growth of e-tourism sector: the case study of Mediterranean countries. MPRA Paper No. 25439. https://mpra.ub.uni-muenchen.de/25439/1/MPRA_paper_ 25439.pdf

McDonough B (2012) An ethnographic study using the work of Heidegger to explore experts' use of information and communication technology (ICT) at work (Doctoral dissertation, London Metropolitan University) 
Menegaki AN, Tiwari AK, Agiomirgianakis GM (2020) Asymmetries in European inbound and outbound tourism: Normal, luxury or inferior good? Fresh evidence from a quantile regression. Eur J Tour Res 25:2508

Meo MS, Chowdhury MAF, Shaikh GM, Ali M, Masood Sheikh S (2018) Asymmetric impact of oil prices, exchange rate, and inflation on tourism demand in Pakistan: new evidence from nonlinear ARDL. Asia Pac J Tour Res 23(4):408-422

Mihalič T (2007) ITC and productivity - the case of the Slovenian travel industry. Product Tour Fund Concept Achiev Growth Compet 2:167

Mosteller F, Tukey JW (1977) Data analysis and regression: a second course in statistics. Addison-Wesley Series in Behavioral Science: Quantitative Methods

Neyman J, Scott EL (1948) Consistent estimates based on partially consistent observations. Econometrica $1-32$

Ntim CG, Lindop S, Thomas DA (2013) Corporate governance and risk reporting in South Africa: a study of corporate risk disclosures in the pre-and post-2007/2008 global financial crisis periods. Int Rev Financ Anal 30:363-383

Papatheodorou A, Rosselló J, Xiao H (2010) Global economic crisis and tourism: consequences and perspectives. J Travel Res 49(1):39-45

Patwary AK, Chowdury MM, Mohamed AE, Azim MS (2020) Dissemination of Information and Communication Technology (ICT) in tourism industry: pros and cons. Int J Multidiscip Sci Adv Technol 1(8):36-42

Perles-Ribes JF, Ramón-Rodríguez AB, Sevilla-Jiménez M, Moreno-Izquierdo L (2016) Unemployment effects of economic crises on hotel and residential tourism destinations: the case of Spain. Tour Manag 54:356-368

Pierdicca R, Paolanti M, Frontoni E (2019) eTourism: ICT and its role for tourism management. J Hosp Tourism Technol. https://doi.org/10.1108/JHTT-07-2017-0043

Poon A (1993) Tourism, technology and competitive strategies. CAB International

Powell D (2016) Quantile regression with nonadditive fixed effects. Quantile Treat Effect 1-28

Rajan A, Manuel B, Sankar KH, Gunasekar S (2016) Technological advancement and tourism: A panel data analysis of ASEAN countries. In: 2016 IEEE international conference on computational intelligence and computing research (ICCIC), pp 1-4

Ramos CM, Rodrigues PM (2013) Research note: the importance of online tourism demand. Tour Econ 19(6):1443-1447

Rotemberg JJ, Saloner G (1994) Benefits of narrow business strategies. Am Econ Rev 1330-1349

Safaeepour M, Goodarzi M (2015) Planning and developing medical tourism in megalopolis Shiraz. Manag Sci Lett 5(1):123-136

Saha S, Yap G (2014) The moderation effects of political instability and terrorism on tourism development: a cross-country panel analysis. J Travel Res 53(4):509-521

Shahzad SJH, Shahbaz M, Ferrer R, Kumar RR (2017) Tourism-led growth hypothesis in the top ten tourist destinations: new evidence using the quantile-on-quantile approach. Tour Manag 60:223-232

Shehzad K, Liu X, Rauf A, Arif M, Mazhar S, Sohail N, Amin W (2019) Revolutionising tourism development in China: an effective role of ICT and Western Silk Road project. Asia Pac J Tourism Res 24(9):965-977

Sigala M (2004) Integrating and exploiting Information and Communication Technologies (ICT) in restaurant operations: implications for restaurant productivity. J Foodserv Bus Res 6(3):55-76

Sreekumar TT, Parayil G (2002) Contentions and contradictions of tourism as development option: the case of Kerala, India. Third World Q 23(3):529-548

Tcheng H, Huet JM, Viennois I, Romdhane M (2007) Telecoms and development in Africa: the chicken or the egg. Convergence Lett $8(16)$

Thompson HG Jr, Garbacz C (2011) Economic impacts of mobile versus fixed broadband. Telecommun Policy 35(11):999-1009

Toy M (2021) The effect of AI implementation on total factor productivity. https://digitalworks.union.edu

Tsaurai K, Chimbo B (2019) Information and communication technology (ICT) led tourism growth nexus in transitional markets. Acta Universit Danubius Econ 15(5)

Tsokota T, Von Solms R, van Greunen D (2017) An ICT strategy for the sustainable development of the tourism sector in a developing country: a case study of Zimbabwe. Electron J Inf Syst Dev Country 78(1):1-20

Velázquez BM, Blasco MF, Gil Saura I (2015) ICT adoption in hotels and electronic word-of-mouth. Academia Revista Latinoamericana De Administración 28(2):227-250 
Vu KM (2011) ICT as a source of economic growth in the information age: empirical evidence from the 1996-2005 period. Telecommun Policy 35(4):357-372

Wang EZ, Lee CC (2022) The impact of clean energy consumption on economic growth in China: is environmental regulation a curse or a blessing? Int Rev Econ Financ 77:39-58. https://doi.org/10. 1016/j.iref.2021.09.008

Waverman L, Meschi M, Fuss M (2005) The impact of telecoms on economic growth in developing countries. Vodafone Policy Pap Ser 2(03):10-24

Wernerfelt B (1995) The resource-based view of the firm: ten years after. Strateg Manag J 16(3):171-174

Westerlund J, Narayan PK, Zheng X (2015) Testing for stock return predictability in a large Chinese panel. Emerg Mark Rev 24:81-100

World Tourism Organization (2019) Tourism Highlights. 2019 Edition I Tourism Market Trends UNWTO URL, http://mkt.unwto.org/publication/unwto-tourism-highlights. Accessed 30 Dec 2019

World Travel and Tourism Council (2019) Travel and tourism economic impact 2019 world from https:// www.wttc.org/-/media/files/reports/economic-impact-research/regions-2019/world2019.pdf

Wright KB (2005) Researching Internet-based populations: advantages and disadvantages of online survey research, online questionnaire authoring software packages, and web survey services. J Comput-Mediat Commun 10(3):JCMC1034

Wu W, Lee CC, Xing W, Ho SJ (2021) The impact of the COVID-19 outbreak on Chinese-listed tourism stocks. Financial Innovation, 7, Article number: 22. https://doi.org/10.1186/s40854-021-00240-6

Zaballos AG, López-Rivas R (2012) Socioeconomic impact of broadband in Latin American and Caribbean countries. Inter-American Development Bank, 220

Zhang T, Wei W, Fu X, Hua N, Wang Y (2019) Exploring the roles of technology, people, and organization in building a tourism destination experience: Insights from the 2nd USA-China tourism research summit and Industry Dialogue. J Destin Mark Manag 12:130-135

Publisher's Note Springer Nature remains neutral with regard to jurisdictional claims in published maps and institutional affiliations.

\section{Authors and Affiliations}

\section{Chien-Chiang Lee ${ }^{1,2} \cdot$ Mei-Ping Chen ${ }^{3} \cdot$ Wenmin $\mathrm{Wu}^{2} \cdot$ Wenwu Xing ${ }^{2}$}

Chien-Chiang Lee

cclee6101@gmail.com

Wenmin Wu

2514005147@qq.com

Wenwu Xing

wenwuxing.hpl@qq.com

1 Research Center of the Central China for Economic and Social Development, Nanchang University, Nanchang, China

2 School of Economics and Management, Nanchang University, Nanchang, China

3 Department of Accounting Information, National Taichung University of Science \& Technology, Taichung, Taiwan 